\title{
Market power in an exhaustible resource market: The case of storable pollution permits
}

\author{
Matti Liski and Juan-Pablo Montero*
}

June 8, 2009

\begin{abstract}
Motivated by the structure of existing pollution permit markets, we study the equilibrium path that results from allocating an initial stock of storable permits to an agent, or a group of agents, in a position to exercise market power. A large seller of permits exercises market power no differently than a large supplier of an exhaustible resource. However, whenever the large agent's endowment falls short of its efficient endowment - allocation profile that would exactly cover its emissions along the perfectly competitive path - market power is greatly mitigated by a commitment problem, much like in a durable-good monopoly. We illustrate our theory with two applications: the U.S. sulfur market and the global carbon market that may eventually develop beyond the Kyoto Protocol.
\end{abstract}

JEL classification: L51; Q28.

${ }^{*}$ Liski<liski@hse.fi> is at the Economics Department of the Helsinki School of Economics. Montero <jmontero@faceapuc.cl> is at the Economics Department of the Pontificia Universidad Católica de Chile (PUC Chile). Both authors are also Research Associates at the MIT Center for Energy and Environmental Policy Research. We thank Denny Ellerman, Bill Hogan, John Reilly, Larry Karp, Juuso Välimäki, Ian Sue-Wing and seminar participants at Harvard University, Helsinki School of Economics, IIOC 2006 Annual Meeting, MIT, PUC Chile, Stanford University, UC Berkeley, Universidade de Vigo, Universite Catholique of Louvain-CORE, University of CEMA, University of Paris 1 and Yale University for many useful comments. Part of this work was done while Montero was visiting Harvard's Kennedy School of Government (KSG) under a Repsol YPF-KSG Research Fellowship. Liski gratefully acknowledges funding from the Yrjö Jahnsson Foundation and Nordic Energy Research Program, and Montero from Instituto Milenio SCI (P05-004F) and BBVA Foundation. 


\section{Introduction}

Markets for trading pollution rights or permits have attracted increasing attention in the last two decades. A common feature in most existing and proposed market designs is the future tightening of emission limits accompanied by firms' possibility to store today's unused permits for use in later periods. This design was used in the US sulfur dioxide trading program ${ }^{1}$ but global trading proposals to dealing with carbon dioxide emissions share similar characteristics. In anticipation of a tighter emission limit, it is in the firms' own interest to store permits from the early permit allocations and build up a stock of permits that can then be gradually consumed until reaching the long-run emissions limit. This build-up and gradual consumption of a stock of permits give rise to a dynamic market that shares many, but not all, of the properties of a conventional exhaustible-resource market (Hotelling, 1931).

As with many other commodity markets, permit markets have not been immune to market power concerns (e.g., Hahn, 1984; Tietenberg, 2006). Following Hahn (1984), there is substantial theoretical literature studying market power problems in a static context but none in the dynamic context we just described. ${ }^{2}$ This is problematic because static markets, i.e., markets in which permits must be consumed in the same period for which they are issued, are rather the exception. ${ }^{3}$ In this paper we study the properties of the equilibrium path of a dynamic permit market in which there is a large polluting agent - that can be either a firm, country or cohesive cartel ${ }^{4}$ - and a competitive fringe of many small polluting agents. ${ }^{5}$ Agents receive for free a very generous allocation of permits for a few periods and then a allocation equal, in aggregate, to the long-term emissions goal established by the regulation. We are interested in studying how the exercise of market power changes as we vary the initial distribution of the overall allocation among the different parties. Depending on individual permit endowments and relative costs of

\footnotetext{
${ }^{1}$ As documented by Ellerman and Montero (2007), during the first five years of the U.S. Acid Rain Program constituting Phase I (1995-99) only 26.4 million of the 38.1 million permits (i.e., allowances) distributed were used to cover sulfur dioxide emissions. The remaining 11.65 million allowances were saved and have been gradually consumed during Phase II (2000 and beyond).

${ }^{2}$ We provided preminaliry discussion of the problem in and Liski and Montero (2006a).

${ }^{3}$ Already in the very early programs like the U.S. lead phasedown trading program and the U.S. EPA trading program firms were allowed to store permits under the so-called "banking" provisions provisions that were extensively used (Tietenberg, 2006).

${ }^{4}$ In Section 4.3 we explain the changes (or no changes) to our equilibrium path from replacing the large firm by a few large firms.

${ }^{5}$ The properties of the perfectly competitive equilibrium path are well understood (e.g., Rubin, 1996).
} 
pollution abatement, the large agent can be either a buyer or a seller of permits in the market, which, in turn, may affect how and to what extent it distorts prices away from perfectly competitive levels.

Existing literature provides little guidance on how individual endowments relate to market power in a dynamic setting with storable endowments. ${ }^{6}$ Agents in our model not only decide on how to sell the stock over time, as in any conventional exhaustible resource market, but also how to consume it as to cover their own emissions. In addition, since permits can be stored at no cost agents are free to either deplete or build up their own stocks. We find that the equilibrium can be described by a simple dichotomy. An intertemporal endowment (i.e., profile of annual endowments) to the large agent results in market power no different from that suggested by exhaustible-resource theory as long as the endowment is above the large agent's "efficient allocation", i.e., the allocation profile that would cover its total emissions along the perfectly competitive path. When the large agent's intertemporal endowment is below its efficient allocation, the conclusions regarding market power follow a logic similar to that of the Coase conjecture for the durable-good monopoly, i.e., market power is limited due to commitment problems, although there are some conceptual differences between the durable-good seller and the permit buyer.

There are important policy implications from these results. The first is that allocations to early years that exceed the large agent's current needs (i.e., emissions) do not necessarily lead to serious market power problems if allocations to later years are below future (expected) needs. The second implication is that any redistribution of permits from the large agent to small agents, all else equal, will make the exercise of market power less likely. This is in sharp contrast with predictions from static models where such redistribution of permits could result in an increase of market power; for example, by moving from monopoly power to equally distorting monopsony power by the large agent. Closely related to the second implication is that our results would make a stronger case for auctioning off the permits instead of allocating them for free. This will necessarily make the large agent a buyer of permits.

We then illustrate the use of our theory with two applications: the existing sulfur market created by the U.S. Acid Rain Program in 1990, and the global carbon market

\footnotetext{
${ }^{6}$ In the context of static permit trading (i.e., one-period market), Hahn (1984) shows that market power vanishes when the permit allocation of the large agent is exactly equal to its "efficient allocation" (i.e., its emissions under perfectly competitive pricing). Hence, an allocation different than the efficient allocation results in either monopoly or monopsony power.
} 
that may eventually develop beyond the Kyoto Protocol. For the sulfur application, we use publicly available data on sulfur dioxide emissions and permit allocations to track down the actual compliance paths of the four largest players in the market, which together account for $43 \%$ of the permits allocated during the generous-allocation years, i.e., 1995-1999. The fact that these players, taken either individually or as a cohesive group, appear as heavy borrowers of permits during and after 2000, practically rules out, according to our theory, market power coming from the initial allocations of permits (more so if these large net-buyers were selling permits during the early years of the program). The carbon application, on the other hand, is much more limited in scope since we do not know yet the type of regulatory institutions that will succeed the Kyoto Protocol in the multinational efforts to stabilize carbon emissions and concentrations. Nevertheless, we ask, as an illustrative exercise, to what extent the proportions used in the Kyoto Protocol to allocate permits among the more developed countries may create market-power problems in an eventual global carbon market beyond Kyoto.

The theoretical result that the equilibrium is more competitive as soon as the allocation implies a net buyer position for the large agent is an instance of the Coase conjecture (Coase, 1972; Bulow, 1982), although the setting is different from what Coase initially considered. The large agent would like to depress prices by committing to a moderate puchasing plan but cannot credibly do so in equilibrium; therefore, it is forced to behave more competitively than in the static analog. It is of more general interest, that the seminal works of Coase and Hotelling can be combined to organize our thinking of how pollution permit markets work. In our framework, the permit allocation to the large agent determines whether the equilibrium is in the domain of Coase or Hotelling. Intuitively, the large agent has two uses for its permit stock: sales revenue maximization and compliance cost minimization. As long as the large agent's holding is above its efficient allocation, it will have no problems in implementing its first-best plan for intertemporal revenue maximization and cost minimization in a credible (i.e., subgameperfect) manner. Furthermore, the way the large agent exercises market power gives rise to an equilibrium path analogous to the path for an exhaustible resource with a large supplier (e.g., Salant, 1976). ${ }^{7}$ We then say the agent is in Hotelling domain. When the large agent's endowment is reduced to its efficient allocation, the revenue maximization

\footnotetext{
${ }^{7}$ Note that our approach is very different from Salant's in that we view firms as coming to the market in each period instead of making a one-time quantity-path announcement at the beginning of the game. There is a large theoretical literature after Salant (1976), including, among others, Newbery (1981), Schmalensee and Lewis (1980), Gilbert (1978). For a survey see Karp and Newbery (1993).
} 
objective drops out and the agent stops trading with the rest of the market; it only uses its stock to minimize costs while reaching the long-run emissions target.

When the large agent's stock falls below its efficient allocation, and hence, becomes a net buyer in the market, it has no means of credibly committing to its first-best purchasing path, i.e., it has entered Coase domain. A subgame-perfect effort to depress prices requires the dominant agent to move away from compliance-cost minimization and to delay purchases. This costly distortion, which is not faced by the seller, limits the scope for market power and thus the overall distortion in the market. ${ }^{8}$

Although understanding the effect of endowment allocations on the performance of a dynamic permit market is our main motivation, it is worth emphasizing that the properties of our equilibrium solution apply equally well to any conventional exhaustible resource market in which the large agent is in both sides of the market. Our results imply, for example, that a dominant agent in the oil market needs potentially a significant fraction of the overall oil stock before being able to exercise market power.

The rest of the paper is organized as follows. The model is presented in Section 2. The characterization of the properties of our equilibrium solution are in Section 3. Extensions of the basic model that account for trends in permit allocations and emissions, long-run market power, the presence of two or more large agents and alternative market structures (e.g., forward contracting) are in Section 4. The applications to sulfur and carbon trading are in Section 5. Final remarks are in Section 6.

\section{The Model}

We are interested in pollution regulations that become tighter over time. A flexible way to achieve such a tightening is to use tradable pollution permits whose aggregate allocation is declining over time. When permits are storable, i.e., unused permits can be saved and used in any later period, a competitive permit market will allocate permits not only across firms but also intertemporally such that the realized time path of reductions is the least cost adjustment path to the regulatory target.

\footnotetext{
${ }^{8}$ While it has been long recognized that an exhaustible-resource buyer faces a dynamic inconsistency problem (see, e.g., Karp and Newbery 1993), the conditions for the Coase conjecture in the resource model have not been well understood. Hörner and Kamien (2004) show that the commitment solutions of the durable-good monopoly and exhaustible-resource monopoly are equivalent. The result of the current paper led us to investigate the general equivalence of the subgame-perfect solutions of the two models (Liski and Montero, 2009). With the help of this other paper, we can link our result to the previous literature (see Section 3.2.).
} 
We start by defining the competitive benchmark model of such a dynamic market. Let $\mathcal{I}$ denote a continuum of heterogenous pollution sources. Each source $i \in \mathcal{I}$ is characterized by a permit allocation $a_{t}^{i} \geq 0$, unrestricted emissions $u_{t}^{i} \geq 0,{ }^{9}$ and a strictly convex abatement cost function $c_{i}\left(q_{t}^{i}\right)$, where $q_{t}^{i} \geq 0$ is abatement. Sources also share a common discount rate $r>0$ per unit of time. We introduce the model in continuous time. The aggregate allocation $a_{t}$ is initially generous but ultimately binding such that $u_{t}-a_{t}>0$, where $u_{t}$ denotes the aggregate unrestricted emissions (no index $i$ for the aggregate variables). Without loss of generality, ${ }^{10}$ we assume that the aggregate allocation is generous only at $t=0$ and constant thereafter:

$$
a_{t}=\left\{\begin{array}{c}
s_{0}+a \text { for } t=0 \\
a \text { for } t>0
\end{array}\right.
$$

where $s_{0}>0$ is the initial 'stock' allocation of permits that introduces the intertemporal gradualism into polluters' compliance strategies. Note that $a \geq 0$ is the long-run emissions limit (which could be zero as in the U.S. lead phasedown program). Assume for the moment that none of the stockholders is large; thus, we do not have to specify how the stock is allocated among agents. Aggregate unrestricted emissions are assumed to be constant over time, $u_{t}=u>a .{ }^{11}$ While the first-period reduction requirement may or may not be binding, we assume that $s_{0}$ is large enough to induce savings of permits.

Let us now describe the competitive equilibrium, which is not too different from a Hotelling equilibrium for a depletable stock market. ${ }^{12}$ First, trading across firms implies

\footnotetext{
${ }^{9}$ Firm's unrestricted emissions - also known as baseline emissions or business as usual emissions are the emissions that the firm would have emitted in the absence of environmental regulation.

${ }^{10} \mathrm{In}$ Section 4, we allow for trends in allocations and unrestricted emissions. In particular, there can be multiple periods of generous allocations leading to savings and endogenous accumulation of the stock to be drawn down when the annual allocations decline. Permits will also be saved and accumulated if unrestricted emissions sufficiently grow, that is, if marginal abatement costs grow faster than the interest rate in the absence of saving. None of these extensions change the essense of the results obtained from the basic model.

${ }^{11}$ Again, this will be relaxed in Section 4.

${ }^{12}$ While we will discuss the differences between dynamic permit markets and exhaustible-resource markets, it might be useful to note two main differences here. First, the permit market still exists after the exhaustion of the excessive initial allocations while a typical exhaustible-resource market vanishes in the long run. This implies that long-run market power is a possibility in the permit market, which, if exercised, affects the depletion period equilibrium. Second, the annual demand for permits is a derived demand by the same parties that hold the stocks whereas the demand in an exhaustible-resource market comes from third parties. This affects the way market power will be exercised, as we will discuss in detail below.
} 
that at all times $t$ marginal costs equal the price,

$$
p_{t}=c_{i}^{\prime}\left(q_{t}^{i}\right), \forall i \in \mathcal{I}
$$

Second, since holding permits across periods prevents arbitrage over time, equilibrium prices are equal in present value as long as some of the permit stock is left for the future use. Exactly how long it takes to exhaust the initial stock depends on the stringency of the long-run reduction target $u-a>0$, and the size of the initial stock $s_{0}$. Let $T$ be the equilibrium exhaustion time. Then, $T$ is such that (1) holds for all $t$, and

$$
\begin{aligned}
d p_{t} / d t & =r p_{t}, 0 \leq t<T \\
q_{T} & =u-a \\
s_{0} & =\int_{0}^{T}\left(u-a-q_{t}\right) d t .
\end{aligned}
$$

These are the three Hotelling conditions that in exhaustible-resource theory are called the arbitrage, terminal, and exhaustion conditions, respectively. Thus, while (1) ensures that polluters equalize marginal costs across space, the Hotelling conditions ensure that firms reach the ultimate reduction target gradually so that marginal abatement costs are equalized in present value during the transition.

We are interested in the effect of market power on this type of equilibrium. To this end, we isolate one agent (or a coherent group of agents), denoted by the index $m$, from $\mathcal{I}$ and call it the large agent. The remaining agents $i \in \mathcal{I}$ are studied as a single competitive unit, called the fringe, for which we will use the index $f$. In particular, the stock allocation for the large agent, $s_{0}^{m}=s_{0}-s_{0}^{f}$, is now large compared to the holdings of any of the other fringe members. The annual allocations $a^{m}$ and $a^{f}$ are constant, as well as the unrestricted emissions $u^{m}$ and $u^{f}$, and still satisfying

$$
u-a=\left(u^{m}+u^{f}\right)-\left(a^{m}+a^{f}\right)>0 .
$$

The fringe's aggregate cost is denoted by $c_{f}\left(q_{t}^{f}\right)$, which gives the minimum cost of achieving the total abatement $q_{t}^{f}$ by sources in $\mathcal{I}$. This cost function is strictly convex, as well as the cost for the large agent, denoted by $c_{m}\left(q_{t}^{m}\right)$.

We look for a Markovian subgame-perfect equilibrium in the game between the large polluter and the fringe. Such a game is best introduced in discrete time so that the timing and strategies become perfectly clear (see the Appendix) but, for ease of exposition, we explain the equilibrium in continuous time in the main text.

At each point $t$, all agents observe the stock holdings of both the large polluter, $s_{t}^{m}$, and the fringe, $s_{t}^{f}$. We simplify the permits market clearing process by letting the large 
agent to announce first its spot sales of permits at $t$, which we denote by $x_{t}^{m}>0(<0$, if the large agent is buying permits). ${ }^{13}$ Having observed stocks $s_{t}^{m}$ and $s_{t}^{f}$ and the large agent's sales $x_{t}^{m}$, fringe members form rational expectations about future supplies by the large agent and make their abatement decision $q_{t}^{f}$ as to clear the market at price $p_{t}$. In equilibrium $p_{t}$ is such that

$$
x_{t}^{f}=-x_{t}^{m}, p_{t}=c_{f}^{\prime}\left(q_{t}^{f}\right) \text { and } d p_{t} / d t \leq r p_{t},
$$

i.e., the price not only eliminates arbitrage possibilities across fringe firms at $t, p_{t}=$ $c_{f}^{\prime}\left(q_{t}^{f}\right)=c_{i}^{\prime}\left(q_{t}^{i}\right), \forall i$, but also across periods. If some of the fringe stock is left for the future, then the latter arbitrage condition in (5) holds as an equality. The fringe stock evolves according to

$$
d s_{t}^{f} / d t=a^{f}-u^{f}+q_{t}^{f}-x_{t}^{f} .
$$

We can assume that the fringe does not observe $q_{t}^{m}$ before abating at $t$, so the decisions on abatement are simultaneous, although the timing with respect to abatement is not essential for the results. ${ }^{14}$

At each $t$ and given stocks $\left(s_{t}^{m}, s_{t}^{f}\right)$, the large agent chooses $x_{t}^{m}$ and decides on $q_{t}^{m}$ knowing that the fringe can correctly replicate the large agent's problem in future subgames. Equilibrium choice $\left(x_{t}^{m}, q_{t}^{m}\right)$ at each $t$ solves

$$
\max \int_{t}^{\infty}\left\{p_{\tau} x_{\tau}^{m}-c_{m}\left(q_{\tau}^{m}\right)\right\} e^{-r(\tau-t)} d \tau
$$

subject to

$$
d s_{t}^{m} / d t=a_{t}^{m}-u_{t}^{m}+q_{t}^{m}-x_{t}^{m}
$$

and (5)-(6).

\section{Characterization of the Equilibrium}

\subsection{Seller power}

It is natural to consider first what happens in the long run, i.e., when both stocks $s_{0}^{m}$ and $s_{0}^{f}$ have been consumed. Since our main motivation is to consider the link between

\footnotetext{
${ }^{13}$ Without the Stackelberg timing for $x_{t}^{m}$ we would have to specify a trading mechanism for clearing the spot market. In a typical exhaustible-resource market the problem does not arise since buyers are third party consumers.

${ }^{14}$ Note that not observing abatement $q$ is most realistic because this information becomes publicly available only at the closing of the period as firms redeem permits to cover their emissions during that period. Assuming the Stackelberg timing not only for $x_{t}^{m}$ but also for $q_{t}^{m}$ does not change the results.
} 
permit stocks and market power, we want to first assume away market power coming from extreme annual allocations that determine the long-run trading positions. It is clear that this source of market power can be ruled out by assuming efficient annual allocations $a^{m *}$ and $a^{f *}$ satisfying ${ }^{15}$

$$
\bar{p}=c_{f}^{\prime}\left(q_{t}^{f}=u^{f}-a^{f *}\right)=c_{m}^{\prime}\left(q_{t}^{m}=u^{m}-a^{m *}\right) .
$$

Under this allocation the large agent chooses not to trade in the long-run equilibrium because the marginal revenue from the first sales is exactly equal to opportunity cost of selling. In other words, $c_{f}^{\prime}\left(q_{t}^{f}\right)-x_{t}^{m} c_{f}^{\prime \prime}\left(q_{t}^{f}\right)=c_{m}^{\prime}\left(q_{t}^{m}\right)$ holds whenever $x_{t}^{m}=0$.

Having defined the efficient annual allocations, $a^{m *}$ and $a^{f *}$, it is natural to define next the efficient stock allocations which have the same conceptual meaning as the efficient annual allocations: these endowments are such that no trading is needed for efficiency during the stock depletion phase. We denote the efficient stock allocations by $s_{0}^{m *}$ and $s_{0}^{f *}$. Then, if the large agent and the fringe choose socially efficient abatement strategies for all $t \geq 0$, their consumption shares of the given overall stock $s_{0}$ are exactly $s_{0}^{m *}$ and $s_{0}^{f *}$. The socially efficient abatement pair $\left(q_{t}^{m *}, q_{t}^{f *}\right)_{t \geq 0}$ is such that $q_{t}=q_{t}^{m *}+q_{t}^{f *}$ satisfies both $c_{f}^{\prime}\left(q_{t}^{f *}\right)=c_{m}^{\prime}\left(q_{t}^{m *}\right)$ and the Hotelling conditions (2)-(4) ensuring efficient stock depletion. We shall show that the share $s_{0}^{m *}$ is the critical stock determining the type of market manipulation, i.e., there is seller power if $s_{0}^{m}>s_{0}^{m *}$, and buyer power otherwise. We define this stock level explicitly for future reference.

Definition 1 Efficient consumption shares of the initial stock, $s_{0}$, are defined by

$$
\begin{aligned}
s_{0}^{m *} & =\int_{0}^{T^{*}}\left(u^{m}-q_{t}^{m *}-a^{m *}\right) d t \\
s_{0}^{f *} & =\int_{0}^{T^{*}}\left(u^{f}-q_{t}^{f *}-a^{f *}\right) d t,
\end{aligned}
$$

where the pair $\left(q_{t}^{m *}, q_{t}^{f *}\right)_{t \geq 0}$ is the socially efficient abatement path.

Let us now assume some division of the stock $\left(s^{m}, s^{f}\right) \neq\left(s^{m *}, s^{f *}\right)$ and consider how the large agent might move the market. It is clear that the stock will be exhausted at

\footnotetext{
${ }^{15}$ Alternatively, we can assume that the long-run emissions goal is sufficiently tight that the long-run equilibrium price is fully governed by the price of backstop technologies, denoted by $\bar{p}$. This seems to a be a reasonable assumption for the carbon market and perhaps so for the sulfur market after recent announcements of much tighter limits for 2010 and beyond. In any case, we allow for long-run market power in Section 4. The relevant question there is the following: how large can the transitory stock be without creating market power that is additional to that coming from the annual allocations.
} 
some point; let $T^{m}$ and $T^{f}$ denote the (endogenous) exhaustion time points for the large agent and the fringe, respectively (in equilibrium these will depend on the remaining stocks). There are three possibilities: (i) all agents, large and small, hold permits until the overall stock is exhausted $\left(T^{m}=T^{f}\right)$; (ii) the large agent depletes its stock first $\left(T^{m}<T^{f}\right)$; or (iii) the small agents deplete their stocks first $\left(T^{m}>T^{f}\right)$. In the first two cases, the fringe arbitrage implies that market prices are equal in present-value throughout the equilibrium. It turns out that case (ii) is consistent with buyer power, arising when $s_{0}^{m}<s_{0}^{m *}$. Only the last case is consistent with seller power coming from a large endowment, i.e., $s_{0}^{m}>s_{0}^{m *}$. In what follows, we will first focus on seller power and show that the equilibrium is constent with Figure 1.

In Figure 1, the manipulated price is initially higher than the competitive price (denoted by $p^{*}$ ) and grows at the rate of interest as long as the fringe is holding some stock. Right after the fringe stock is exhausted, denoted by $T^{f}$, the manipulated price grows at a lower rate. As a monopoly stockholder, the large agent is now equalizing marginal revenues rather than prices in present value until the end of the storage period, $T^{m}$. The exercise of market power implies extended overall exhaustion time, $T^{m}>T^{*}$, where $T^{*}$ is the socially optimal exhaustion period for the overall stock $s_{0}$, as defined by conditions (2)-(4). Thus, the large agent manipulates the market by saving too much of the stock, which shifts the initial abatement burden towards the fringe and leads to initially higher prices.

The equilibrium conditions that support this outcome are the following. First, as long as the fringe is saving some stock for future uses, prices must be equal in present value, implying that the market-clearing abatement for the fringe must satisfy

$$
d c_{f}^{\prime}\left(q_{t}^{f}\right) / d t=r c_{f}^{\prime}\left(q_{t}^{f}\right) \text { for all } 0 \leq t<T^{f} .
$$

Second, the large agent's equilibrium strategy is such that the gain from selling a marginal permit should be the same in present value for different periods. In this context, however, it is not obvious what is the appropriate marginal revenue concept, since the large agent is selling to other stockholders who adjust their storage decisions in response to sales. Nevertheless, the storage response will not change the principle that the presentvalue marginal gain from selling should be the same for all periods. Because in any period after the fringe exhaustion this gain is just the marginal revenue without the storage response, it must be the case that the subgame-perfect equilibrium gain from selling a marginal unit at any $t<T^{f}$ is equal, in present value, to the marginal revenue from sales at any $t>T^{f}$. The condition that ensures this indifference is the following 


$$
d\left[c_{f}^{\prime}\left(q_{t}^{f}\right)-x_{t}^{m} c_{f}^{\prime \prime}\left(q_{t}^{f}\right)\right] / d t=r\left[c_{f}^{\prime}\left(q_{t}^{f}\right)-x_{t}^{m} c_{f}^{\prime \prime}\left(q_{t}^{f}\right)\right]
$$

for all $0 \leq t<T^{m}$. Note that $c_{f}^{\prime}\left(q_{t}^{f}\right)-x_{t}^{m} c_{f}^{\prime \prime}\left(q_{t}^{f}\right)$ is the equilibrium marginal revenue from sales to the fringe at time at $t$.

Third, the large agent must not only achieve revenue maximization but also compliance cost minimization which is obtained by equalizing present-value marginal costs and, therefore,

$$
d c_{m}^{\prime}\left(q_{t}^{m}\right) / d t=r c_{m}^{\prime}\left(q_{t}^{m}\right)
$$

must hold for all $0 \leq t<T^{m}$. Finally, the large agent's strategy in equilibrium must be such that the gain from selling a marginal permit equals the opportunity cost of selling, that is,

$$
c_{f}^{\prime}\left(q_{t}^{f}\right)-x_{t}^{m} c_{f}^{\prime \prime}\left(q_{t}^{f}\right)=c_{m}^{\prime}\left(q_{t}^{m}\right)
$$

must hold for all $t$.

We can now state the condition for the above equilibrium outcome.

Proposition 1 If $s_{0}^{m}>s_{0}^{m *}$, then conditions (10)-(13) describe a subgame-perfect equilibrium.

Proof. See the Appendix.

The equilibrium is found by solving the commitment solution, where the large agent commits to a path $\left(x_{t}^{m}, q_{t}^{m}\right)_{t \geq 0}$ at time $t=0$, and showing that this solution identifies the subgame-perfect equilibrium path. The equilibrium determines, for any given remaining stocks $\left(s_{t}^{m}, s_{t}^{f}\right)$, the time it takes for the large agent and fringe to sell their stocks such that at each time the stocks and the large agent's optimal actions are as previously anticipated. For initial stocks $\left(s_{0}^{m}, s_{0}^{f}\right)$, the time period is $T^{f}$ for the fringe and $T^{m}$ for the large agent. If for some reason the stocks go off the equilibrium path, the equilibrium exhaustion times change, but the equilibrium is still characterized as above.

The above description of market power is qualitatively consistent with Salant (1976) who considered a large oil seller facing a competitive fringe. However, when the large agent's allocation falls below the efficient share this connection is broken. We turn next to this case.

\subsection{Buyer power}

When the large agent has a stock exactly equal to the efficient share of the overall stock, $s_{0}^{m}=s_{0}^{m *}$, conditions (10)-(13) identify the socially efficient depletion path with $x_{t}^{m}=0$ 


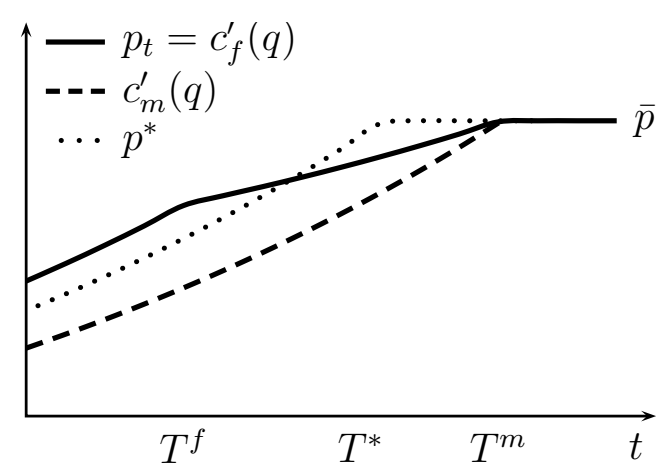

Figure 1: Equilibrium under seller power: $s^{m}>s^{m *}$

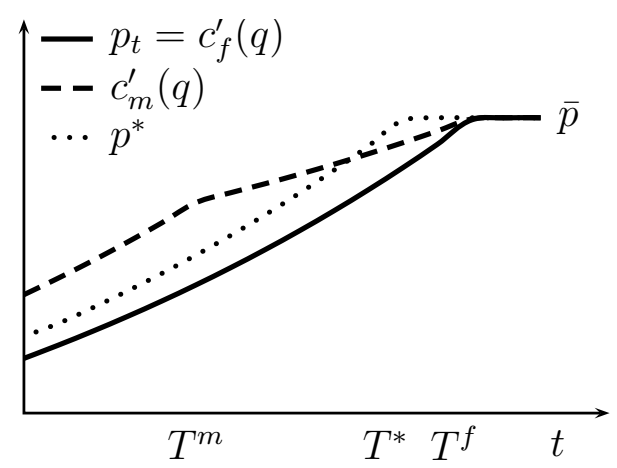

Figure 2: Equilibrium under buyer power: $s^{m}<s^{m *}$

for all $t$, and then also $T^{m}=T^{f}=T^{*}$. The large agent has no incentives to trade with the rest of the market when its stock endowment equals the efficient allocation, leading to the efficient equilibrium path. But when $s_{0}^{m}<s_{0}^{m *}$, the large agent's holding falls short of what it needs for minimizing compliance costs. For if the agent does not purchase permits from the fringe but consumes only from its own stock $s_{0}^{m}$, it must run out of permits before the fringe, implying both $T^{m}<T^{f}$ and that $c_{m}^{\prime}\left(q_{t}^{m}\right)$ exceeds the market price at $t=T^{m}$. This is cannot hold in equilibrium, however, so the large agent is necesarily a buyer whenever $s_{0}^{m}<s_{0}^{m *}$.

Figure 2 depicts an equilibrium path in the presence of buyer power. As long as the buyer is holding stock $\left(t<T^{m}\right)$, it can minimize costs, i.e., present-value marginal costs are equalized as expressed in condition (12). Any abatement path $c_{m}^{\prime}\left(q_{t}^{m}\right)$ that does not satisfy this requirement but leads to exhaustion at $T^{m}$, leaves room to the buyer to improve upon it without interacting with the market. Therefore, $c_{m}^{\prime}\left(q_{t}^{m}\right)$ must grow at the rate of interest as long as $s_{t}^{m}>0$.

The second equilibrium condition is (10), i.e., the permit price must grow at the rate of interest to the very end of the exhaustion of the overall stock, which takes place when the fringe runs out of its stock at $t=T^{f}$. We must have that $T^{m} \leq T^{f}$, because otherwise the equilibrium would be in the domain of the seller-power case. Indeed, this inequality is strict, $T^{m}<T^{f}$, because the buyer will be able to distort the equilibrium by delaying the overall exhaustion time, which leads to lower present-value purchasing costs $\left(T^{m}=T^{f}\right.$ would imply efficiency by conditions (12) and (10)). This is depicted in Figure 2, where the equilibrium price path lies below the buyer's marginal cost for all $t<T^{f}$ (the efficient price path is the dotted line). 
Note that the gap between the marginal cost and price, $c_{m}^{\prime}\left(q_{t}^{m}\right)-p_{t}$, declines in the final part of the equilibrium, $T^{m}<t<T^{f}$. Here the buyer has no stock of its own but it buys from the fringe stock. In the Appendix, we derive the following condition describing the buyer's equilibrium cost and benefit from reducing purchases by one marginal unit,

$$
c_{m}^{\prime}\left(q_{t}^{m}\right)=p_{t}+\frac{r p_{t} X_{t}}{u_{t}^{f}-a_{t}^{f}-q_{t}^{f}+x_{t}^{f}} \quad \text { for } T^{m}<t<T^{f},
$$

where $X_{t}$ is defined as the remaining purchases by the large agent from time $t$ on along the equilibrium path, and $u_{t}^{f}-a_{t}^{f}-q_{t}^{f}+x_{t}^{f}=-d s_{t}^{f} / d t>0$. The left-hand side of (14) gives the cost of reducing purchases by a marginal unit, i.e., marginal abatement costs.

The first term in the right-hand side of (14) is the saving from not buying the permit unit rather than abating. The second term is the gain from having lower prices for remaining purchases. In continuous time, a marginal reduction in today's purchase leads to a marginal delay in the arrival of the long-run equilibrium which, in turn, depresses equilibrium prices by $r p_{t}$. This leads to a total purchase cost reduction of size $r p_{t} X_{t}$ that divided by $-d s_{t}^{f} / d t$ gives the marginal gain. To understand why this term is divided by $-d s_{t}^{f} / d t$ and not simply by the actual purchase $x_{t}^{f}$, note that the fringe stock is "lost" at this rate, so delaying the long-run equilibrium becomes less effective the faster is the fringe own usage of the stock (i.e., the large is $u_{t}^{f}-a_{t}^{f}-q_{t}^{f}$ ). If the fringe is not polluting at all $\left(u_{t}^{f}-a_{t}^{f}-q_{t}^{f}=0\right)$, the buyer could delay the long-run equilibrium in one marginal unit of time, i.e, $d t$, by just refraining from buying $x_{t}^{f}$. But when the fringe is also using permits for compliance, the large agent must make an extra effort to effectively postpone the arrival of the long-run equilibrium in one period; he must save $x_{t}^{f}$ plus $u_{t}^{f}-a_{t}^{f}-q_{t}^{f}$.

We can now put together the description of equilibrium when $0 \leq s_{0}^{m}<s_{0}^{m *}$. As depicted in Figure 4, the buyer's marginal cost is increasing at rate $r$ up to $T^{m}$ and it remains higher than the equilibrium price, which grows at rate $r$ to the end of the equilibrium at $T^{f}$ (note that $T^{m}=0$ when $s_{0}^{m}=0$ ). The fringe is willing to sell at lower prices because the buyer can credibly delay its consumption according to (14) after its own exhaustion, $T^{m}<t<T^{f}$.

Proposition 2 If $0 \leq s_{0}^{m}<s_{0}^{m *}$, the above description is a subgame-perfect equilibrium.

Proof. See the Appendix.

Let us now connect this result to a wider literature to better understand its meaning. Note that as opposed to the seller case $\left(s_{0}^{m}>s_{0}^{m *}\right)$, the buyer of permits cannot implement its first best: the buyer would like to commit to a single large purchase with the market, leading to a lower price than described above (we discuss this in detail in the next section). 
However, the buyer faces a time-inconsistency problem similar to that of a durable-good monopolist (Coase, 1972; Bulow, 1982). The connection between exhaustible resources (the permit stock in our case) and durable-goods has been long recognized (see, e.g., Karp and Newbery, 1993). In fact, Hörner and Kamien (2004) show that the commitment solutions to the durable-good monopoly and exhaustible-resource monopsony are formally equivalent. But Liski and Montero (2009) were the first to recognize the differences in the subgame-perfect solutions of the two problems.

For durable goods, the stock is the consumer population already served, and, if consumer valuation declines with the stock, low-valuation consumers are expected to be served at some point in the future. This creates incentives to consumers to wait for lower prices in the future, and this is the reason why the commitment solution is not subgame perfect. If consumers are patient enough (or sales arbitrarily frequent), the conjecture says that the durable-good monopoly is forced to lower prices to the lowest-valuation level. For exhaustible resources, the value changing with the stock is the cost of extracting the resource from the ground. The conjecture, in connection with the resource monopsony, then says that sellers can wait for high-cost sellers to enter the market, and thereby, forcing the buyer to raise prices to the highest-cost level. In both cases, the conjecture requires market valuations (either consumer valuation or producer cost) to change with the stock.

In our case, there is no extraction cost, i.e., the cost of selling permits from the stock is zero ${ }^{16}$ and, hence, it would seem that the commitment problem suggested by the durable-good analog is absent. However, Liski and Montero (2009) show that the existence of a choke price alone is enough for the buyer's commitment problem to arise (in this paper, the choke price would be the long-run equilibrium price; not the price above which the demand for the resource falls to zero). Moreover, the choke price shapes the surplus-sharing in a way that is unique to the resource model. The equilibrium condition (14) describing the buyer's purchases is equivalent to the equilibrium consumption rule derived for the exhaustible-resource monopsony in Liski and Montero (2009). However, the scope for market power is considerably reduced here for two reasons specific to the pollution context: (i) the presence of many small polluting agents that free-ride on the large agent's effort to depress permit prices (i.e., the seller side is also consuming from the remaining stock) and (ii) the substantial cost the large agent may incur from postponing the arrival of the long-run emissions goal (unless the long-run goal is to total phase out

\footnotetext{
${ }^{16}$ Note that the abatement cost has nothing to do with extraction costs. From the abatement cost we can derive the buyer's utility from consumption, so it defines the buyer's flow valuation for the good.
} 
pollution).

\subsection{Welfare comparison}

We will now argue that a deviation from the efficient allocation creating a large seller results in a much larger welfare loss than a deviation of the same size creating a large buyer. In this sense, the dynamics introduced by the permit stock allocation mitigates (exacerbates) the market power problem when the large agent is on the buyer (seller) side of the market.

Consider first a benchmark case: a static version of the model where firms only receive a constant flow allocation. The equilibrium satisfies the usual marginal-revenue equals marginal cost

$$
c_{f}^{\prime}\left(q_{t}^{f}\right)-x_{t}^{m} c_{f}^{\prime \prime}\left(q_{t}^{f}\right)=c_{m}^{\prime}\left(q_{t}^{m}\right) .
$$

Assume further that all firms have linear marginal abatment costs. In this linear case, a given deviation from the efficient permit allocation leads to the same welfare loss independently of whether this deviation makes the large agent a seller or buyer (i.e, regardless of whether we are reallocating a given number of permits from the fringe to the large agent or vice versa).

Let us see now how this symmetry in the welfare distortion can be exported to the dynamic case. Marginal costs are still linear and, in addition to the flow allocations, firms also recieve a stock allocation, as we have assumed throughout the paper. Suppose further that the large agent is artificially restricted to trade only once with the market at time $t=0$. For the a given deviation from the efficient permit endowments, Figures 3 and 4 depict how a seller $\left(s_{0}^{m}>s_{0}^{m *}\right)$ and a buyer $\left(s_{0}^{m}<s_{0}^{m *}\right)$ would trade, respectively. The seller would restrict supplies to increase the price level above the efficient price path $p_{t}^{*}$ and use more permits for compliance than what is socially optimal. This leads to a lower than efficient marginal cost path $c_{m}^{\prime}$. For the buyer, the equilibrium is a mirror image, with the roles of marginal cost and price reversed. As in the static case, the welfare losses are again the same regardless of whether the (same) deviation makes the large agent a buyer or seller.

This artificial description does not correspond to the true dynamic equilibrium, however. Removing the one-time trading restriction helps the seller $\left(s_{0}^{m}>s_{0}^{m *}\right)$ but hurts the buyer $\left(s_{0}^{m}<s_{0}^{m *}\right)$. We have already proved these conclusions in our equilibrium descriptions. The equilibrium described in Figure 1 is found by solving the commitment solution, where the large agent commits to a path $\left(x_{t}^{m}, q_{t}^{m}\right)_{t \geq 0}$ at time $t=0$ (see the Ap- 


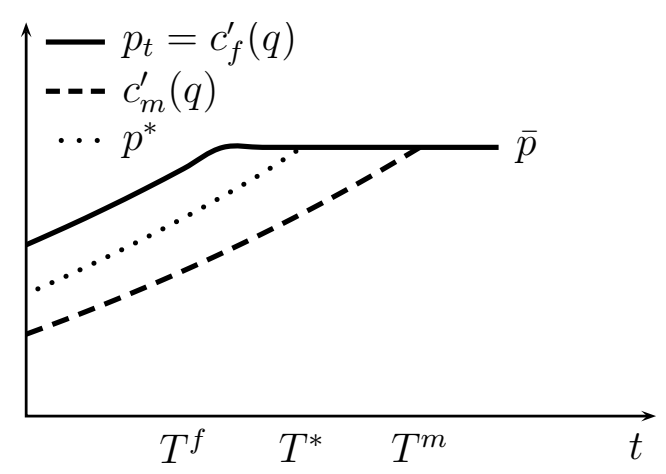

Figure 3: Equilibrium under one-time transaction by large seller: $s^{m}>s^{m *}$

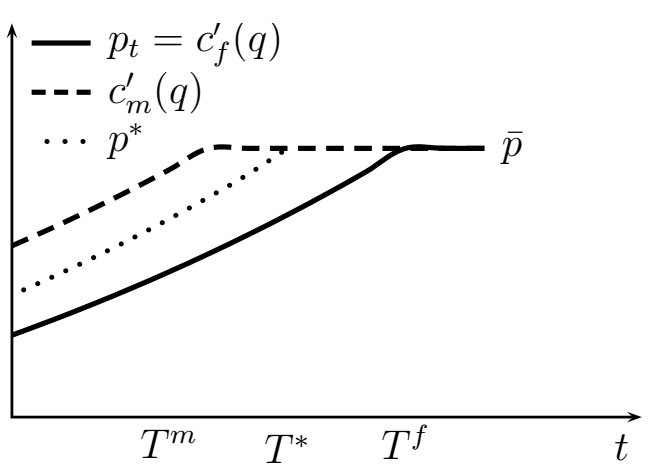

Figure 4: Equilibrium under one-time transaction by large buyer: $s^{m}<s^{m *}$

pendix for Proposition 1 where we show that the subgame-perfect path is identical to the commitment path). The seller could also commit to the path in Figure 3, corresponding to the static analog, but he chooses not to do so. Therefore, the true dynamic equilibrium leaves the seller strictly better off, i.e., he can distort the equilibrium more than in the static analog of Figure 3. The reason for the difference is that the seller can commit to ration supplies in the final part of equilibrium path, to implement the monopoly phase with market prices declining in present value after the fringe exhaustion (see Figure 1).

For the buyer, however, Figure 4 represents the first-best outcome given the fringe perfection constraint that prices must go up a the rate of interest. In this solution, the buyer minimizes its compliance costs and restricts purchases through commitment not to enter the market again. In contrast, in subgame-perfect equilibrium, the buyer can credibly restrict his demand only by distorting abatement in the final part of the equilibrium; see Figure 2 and the time interval from $T^{m}$ to $T^{f}$ where the buyer's marginal cost declines in present value.

Stated differently, buyer power $\left(s_{0}^{m}<s_{0}^{m *}\right)$ distorts the dynamic equilibrium less, in the above sense, than seller power $\left(s_{0}^{m}>s_{0}^{m *}\right)$ because in the former case the large agent implements the welfare loss by deviating from his own cost minimization whereas in the latter the fringe is forced to distort its cost minimization. While this illustration was based on linear marginal costs, it illustrates the general point that endowments falling short of the efficient allocation create a commitment problem to the large agent, similar to that of a durable-good monopoly, and this reduces the welfare loss arising from the allocation.

We conclude this section with a simple numerical exercise illustrating the welfare 
differences. The large agent and the fringe are identical in all respects but in stock allocations. We assume linear marginal costs, $c_{m}^{\prime}=c_{f}^{\prime}=q$, and $u^{f}=u^{m}=2, a^{f}=a^{m}=$ $1, r=0.1$ and $s_{0}=s_{0}^{f}+s_{0}^{m}=5$. In this illustration we compare the efficient outcome $\left(s_{0}^{m}=s_{0}^{m *}\right)$ to two extreme cases: (i) the large agent receives no stock (pure monopsony) and (ii) the agent receives the full stock (pure monopoly). The long-run price is 1 in all cases, and, as the first row of Table 1 shows, an overall stock evenly allocated between the two parties allows for initial price of .449 and a long-run price to be reached at $T=8$. The second row of the table shows that full monopsony power depresses the price only slightly to .429 and extends exhaustion time only by 6 per cent (from 8 to 8.5 ). More importantly, the overall efficiency loss is only 7 per cent. Moving to the other extreme allocation, we see a considerable increase in both the initial price and the exhaustion time (55 and 19 per cent, respectively). Not surprisingly, this leads to a significant welfare loss of 28 per cent. ${ }^{17}$

\begin{tabular}{c|c|c|c} 
& $p_{0}$ & $T$ & loss \\
\hline$s_{0}^{m}=s_{0}^{m *}$ & .449 & 8 & 0 \\
\hline$s_{0}^{m}=0$ & .429 & 8.5 & .07 \\
\hline$s_{0}^{m}=s_{0}$ & .694 & 9.5 & .28
\end{tabular}

Table 1: Illustration of distortions under monopsony (the second row) and monopoly (the third row). Notation: $p_{0}=$ initial price, $T=$ overall exhaustion time, loss=increase in total costs relative to efficient solution.

\section{Extensions}

\subsection{Trends in allocations and emissions}

In most cases the transitory compliance flexibility is not created by a one-time allocation of a large stock of permits but rather by a stream of generous annual allocations, as in the U.S. Acid Rain Program (see footnote 1). In a carbon market, the emissions constraint is likely to become tighter in the future not only due to lower allocations but also to significantly higher unrestricted emissions prompted by economic growth. This is particularly so for economies in transition and developing countries whose annual permits

\footnotetext{
${ }^{17}$ Note that if marginal abatment cost were strictly convex, welfare differences would be even higher. See Hahn (1984) for a numerical example for the static case.
} 
may well cover current emission but not those in the future as economic growth takes place.

To cover these situations, let us now consider aggregate allocation and unrestricted emission sequences, $\left(a_{t}, u_{t}\right)_{t \geq 0}{ }^{18}$ such that the reduction target $u_{t}-a_{t}$ changes over time in a way that makes it attractive for firms to first save and build up a stock of permits and then draw it down as the reduction targets become tighter. ${ }^{19}$ As long as the market is leaving some stock for the next period, the efficient equilibrium is characterized by the Hotelling conditions, with the exhaustion condition replaced by the requirement that aggregate permit savings are equal to the stock consumption during the stock-depletion phase. $^{20}$

Although the stock available is now endogenously accumulated, each agent's efficient share of the stock at $t$ can be defined almost as before: it is a stock holding at $t$ that just covers the agent's future consumption net of the agent's own savings. Let us now consider the efficient shares for the large agent and fringe, facing reduction targets given by $\left(a_{t}^{m}, u_{t}^{m}\right)_{t \geq 0}$ and $\left(a_{t}^{f}, u_{t}^{f}\right)_{t \geq 0}$. Then, the large agent's efficient share of the stock at $t$ is just enough to cover the large agent's future own net demand:

$$
s_{t}^{m *}=\int_{t}^{T}\left(u_{\tau}^{m}-q_{\tau}^{m *}-a_{\tau}^{m}\right) d \tau,
$$

where $q_{\tau}^{m *}$ denotes the socially efficient abatement path for the large agent. On the other hand, the socially efficient stock holdings, which are denoted by

$$
\hat{s}_{t}^{m}=\int_{0}^{t}\left(a_{\tau}^{m}-u_{\tau}^{m}+q_{\tau}^{m *}\right) d \tau
$$

will typically differ from $s_{t}^{m *}$.

\footnotetext{
${ }^{18}$ We continue assuming that $\left(a_{t}, u_{t}\right)_{t \geq 0}$ is known with certainty. Uncertainty would provide an additional storage motive, besides the one coming from tightening targets, as in standard commodity storage models (Williams and Wright, 1991). It seems to us that uncertainty may exacerbate the exercise of market power, but the full analysis and the effect on the critical holding needed for market power is beyond the scope of this paper.

${ }^{19}$ If the reduction target increases because of economic growth, as in climate change, it is perhaps not clear why the marginal costs should ever level off. However, the targets will also induce technical change, implying that abatement costs will also change over time (see, e.g., Goulder and Mathai, 2000). While we do not explicitly include this effect, it is clear that the presence of technical change will limit the permit storage motive.

${ }^{20}$ Obviously, the same description applies irrespective of whether savings start at $t=0$ or at some later point $t>0$, or, perhaps, at many distinct points in time. The last case is a possibility if the trading program has multiple distinct stages of tightening targets such that the stages are relatively far apart, i.e., one storage period may end before the next one starts.
} 
Clearly if $\hat{s}_{t}^{m} \geq s_{t}^{m *}\left(\hat{s}_{t}^{m} \leq s_{t}^{m *}\right)$ for all $t$, the equilibrium path will exhibit seller (buyer) power throughout as described in Section 3.1 (3.2). Let us then illustrate a somewhat more intricate situation where the profile of permit endowments leads to both buyer and seller power during the equilibrium path - we will not dwell on analyzing all the conceivable cases because in the end they are coved by principles identified before.

The most interesting case is one in which the permits allocation of the large agent is such that the large agent starts buying permits in the market to later become a net seller. The case is depicted in Figure 5. The two solid lines correspond to the large agent's allocation profile $\left(a_{t}^{m}\right)$ and its socially efficient emission path $\left(u_{t}^{m}-q_{t}^{m *}\right)$. Assume further that the areas in the figure are such that $B-A=C$, which implies that large agent's cumulative allocation is exactly equal to its cumulative emissions along the efficient path. Suppose for a moment that the market has indeed followed the efficient path from $t=0$ to $t=t^{\prime}$ (requiring the large agent to have bought a total of $A$ permits in the market). But at $t=t^{\prime}$, Proposition 1 indicates that the market cannot longer follow the efficient path because $B>C$. Since the equilibrium of the continuation game at $t=t^{\prime}$ suffers from seller power, the true equilibrium path starting at $t=0$ must have a noncompetitive shape. Note, however, that because the large agent is also able to exercise buyer power during the earlier periods - when he is short of permits - he is able to depress prices somewhat by buying less than $A$ and delaying purchases beyond $t^{\prime}$. But since buyer power is much less of a problem than seller power, prices at $t=0$ are likely to be above competitive levels, although explicit results would require more specific assumptions.

The example above indicates that moving to a less competitive equilibrium may benefit the fringe but not the large agent: he may need to buy permits at higher than competitive prices to comply and then sell them, on average, at lower prices later on when his allocation becomes more generous. Thus, the gains from market manipulation spill over to fringe asset values. Although using future allocations for current compliance is ruled out by regulatory design, ${ }^{21}$ the large agent can restore the perfectly competitive solution as a subgame-perfect equilibrium by swapping part of its far-term allocations for near-term allocations of competitive agents. ${ }^{22}$

\footnotetext{
${ }^{21}$ In all existing and proposed market designs firms are not allowed to "borrow" permits from far-term allocatios to cover near-term emissions (Tietenberg, 2006).

${ }^{22}$ Although not necessarily related to the market power reasons discussed here, it is interesting to note that swap trading is commonly used in the US sulfur market (see Ellerman et al., 2000).
} 


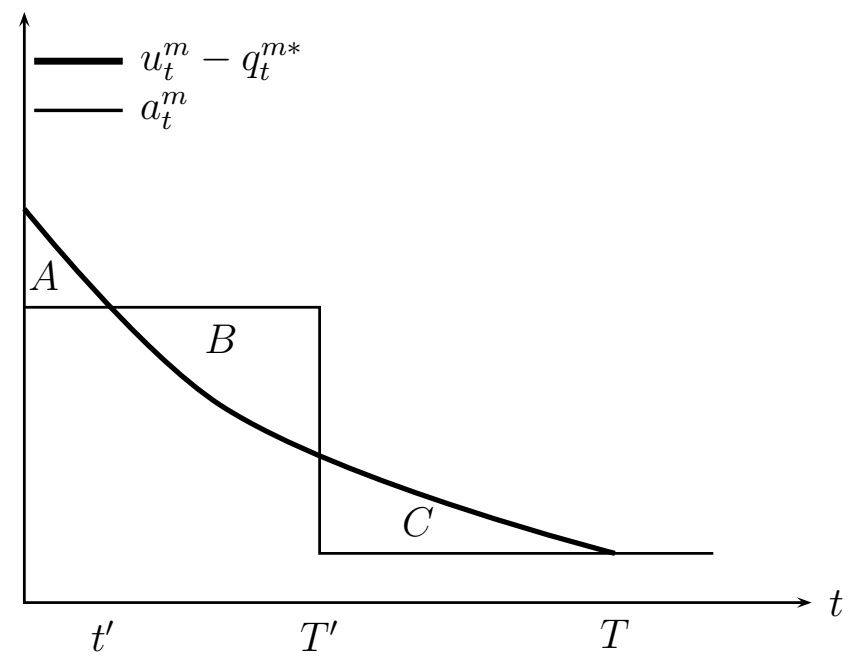

Figure 5: Allocation path leading to both buyer and seller power

\subsection{Long-run market power}

So far we have considered situations where after the exhaustion of the overall stock firms follow perfect competition. This is the result of assuming either that the large agent's long-run permit allocation is close to its long-run competitive emissions or that the longrun equilibrium price of permits is fully governed by the price of backstop technologies (see (9) and footnote 15). While the long-run perfect competition assumption may be reasonable for both of our applications below, it is still interesting to explore the implications of long-run market power on the evolution of the permits stock. Since long-run market power is intimately related to the large agent's long-run annual allocation relative to its emissions, it should be possible to make a distinction between the market power attributable to the long-run annual allocations and the transitory market power attributable to the stock allocations.

The first relevant case is that of long-run monopoly power, illustrated in Figure 6. For clarity, we assume that long-run allocations are constant. Then, the long-run market power coming from an annual allocation $a^{m}>a^{m *}$ implies a higher than competitive 
long-run equilibrium price $p_{L R}^{m}>p_{L R}^{*}$. Whether there is any further transitory market power coming from the stock allocation depends, as in previous sections, on the large agent's share of the transitory stock. The equilibrium without transitory market power is characterized by a competitive storage period with a distorted terminal price at $p_{L R}^{m}>$ $p_{L R}^{*}$, where the ending time is such that both the fringe and the large agent are holding stock to the very end of the storage period. This path is depicted in Figure 6 as $p_{0}^{m}$. The critical stock is defined by this path as the stock holding that just covers the large agent's own compliance needs while taking into account the trading activity imposed by the long-run equilibrium (before the exhaustion of the overall stock the large agent will be selling to the fringe). ${ }^{23}$ Note that the overall stock is depleted faster than what is socially optimal, $T^{*}$, because the long-run monopoly power allows the large agent to commit to consuming more than the efficient share of the available overall allocation.

The transitory market power that arises for stock holdings above the critical level (i.e., seller power) leads to an equilibrium price path $p_{t}^{m}$ with a familiar shape. This path reaches price $p_{L R}^{m}$ at $t=T^{m}$, which can be smaller or greater than $T^{*}$ depending on whether the long-run shortening effect is greater or smaller than the transitory extending effect. In contrast, the transitory market power that arises for stock holdings below the critical level would depress the price path (for clarity, this path has been omitted from the figure).

The second relevant case, which is illustrated in Figure 7, is that of long-run monopsony power, i.e., $p_{L R}^{m}<p_{L R}^{*}$. Here, the equilibrium price path without transitory market power $\left(p_{0}^{m}\right)$ stays below the socially efficient path $\left(p^{*}\right)$ throughout. Again, this path defines the critical stock for transitory market power as the holding that allows compliance cost minimization while taking into account the trading activity imposed by the long-run equilibrium (in this case, the large will be buying from the fringe before the exhaustion of the overall stock). For stockholdings above this critical level, the large agent has more than its own need during the transition, so that the equilibrium price path $\left(p_{t}^{m}\right)$ has again the familiar shape. Note that the transitory motive of keeping marginal net revenues equalized in present value extends the overall depletion period further in addition to the extension coming from the long-run monopsony power and, therefore, $T^{m}$ is unambiguously greater than $T^{*}$. Note also that the path $p_{t}^{m}$ could very well be above

\footnotetext{
${ }^{23}$ To estimate the large agent's critical stockholding, first let both $c_{m}^{\prime}\left(q_{t}^{m}\right)$ and $p_{t}=c_{f}^{\prime}\left(q_{t}^{f}\right)$ go up at the interest until reaching their long-term levels $\left(c_{m}^{\prime}\left(q_{L R}^{m}\right)\right.$ and $p_{L R}^{m}$, respectively, with $\left.c_{m}^{\prime}\left(q_{L R}^{m}\right)<p_{L R}^{m}\right)$ and while satisfying the exhaustion condition, and then compute the cumulative emissions above the long-run level $u^{m}-q_{L R}^{m}$.
} 


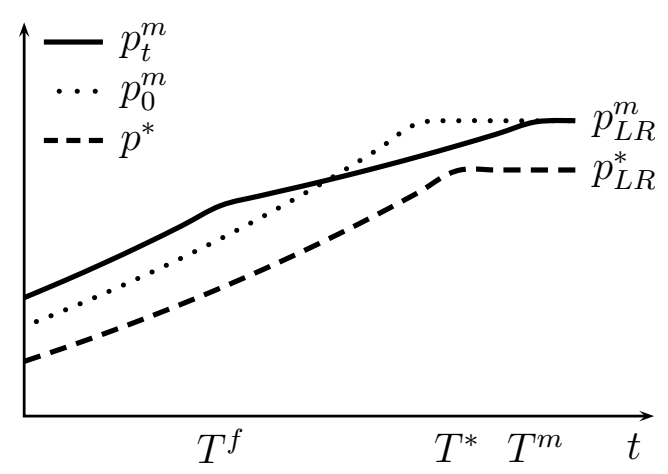

Figure 6: Short- and long-run seller power

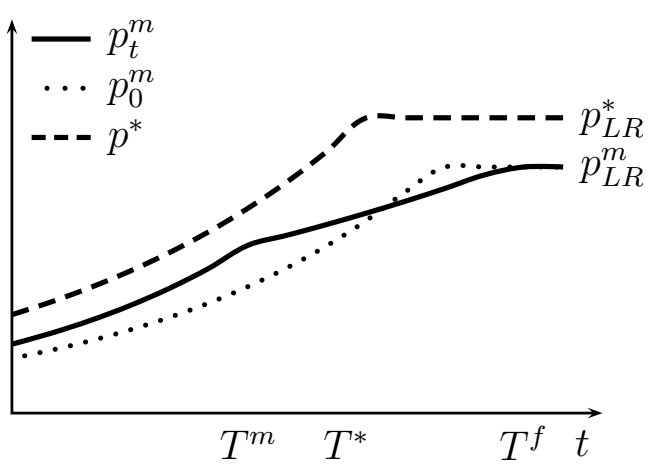

Figure 7: Short-run seller power and long-run buyer power

$p^{*}$ during the early part of the equilibrium if the market power coming from the stock allocations proves to be stronger than the one coming from the flow allocations. ${ }^{24}$

\subsection{Multiple large agents}

We now discuss how the characterization of the equilibrium presented in Section 3 changes as we consider two or more large (strategic) firms sharing the market with the fringe of competitive firms. To simplify the exposition consider just two strategic firms and denote them by $i$ and $j$. Notation and the timing of the game are as before: at the beginning of period $t$ and having observed the stock vector $\left(s_{t}^{i}, s_{t}^{j}, s_{t}^{f}\right)$, strategic firms simultaneously announce their spot sales/purchases $x_{t}^{i}$ and $x_{t}^{j}$; based on these announcements and the stock vector, fringe firms clear the spot market by setting, on aggregate, $x_{t}^{f}=-x_{t}^{i}-x_{t}^{j}$. Unlike in the basic model with a single strategic player, here we require the fringe to be sufficiently large as to clear the market for any possible equilibrium pair $\left(x_{t}^{i}, x_{t}^{j}\right){ }^{25}$

Neglect for the moment any long-run market power and focus exclusively on market power during the depletion of the stocks (we will come back to long-run market power at the end of the section). Depending on the initial share of the stock and firms' costs, there are three cases to consider : (i) both strategic firms are on the supply side of the market, (ii) both firms are on the demand side; and (iii) firm $i$ is on the supply side and $j$ is on the demand side. Note that unless $i$ and $j$ are identical in all respects (i.e., allocations

\footnotetext{
${ }^{24}$ The case of buyer-power during the transition phase is straightforward and, hence, omitted.

${ }^{25}$ If the fringe were too small we would have to rely on a different equilibrium concept, for example, like the one proposed by Hendricks and McAfee (2009) for the case in which the market is populated exclusively by large buyers and sellers. See Yates and Malueg (2009) for an application to pollution permit markets.
} 
and abatement costs), case (iii) will always arise at some point along the depletion path. We will rely on a two-period analysis, which will provide us with all the relevant results for our discussion (one may think of the last two periods before the long-run equilibrium is reached). We have relegated most of the technical analysis to the Appendix, so below we concentrate on the main results.

Consider first case (i). There are two periods $t=1,2$ and initial stock holdings such that $s_{1}^{i}, s_{1}^{j}>0$ and $s_{1}^{f}=0$. We find that spot actions for $i=i, j$ are described by conditions

$$
\begin{aligned}
& c_{f}^{\prime}\left(q_{2}^{f}\right)-x_{2}^{i} c_{f}^{\prime \prime}\left(q_{2}^{f}\right)-c_{i}^{\prime}\left(q_{2}^{i}\right)=0 \\
& c_{f}^{\prime}\left(q_{1}^{f}\right)-x_{1}^{i} c_{f}^{\prime \prime}\left(q_{1}^{f}\right)-c_{i}^{\prime}\left(q_{1}^{i}\right)=0 .
\end{aligned}
$$

One may thus argue that the two strategic sellers behave, at least qualitatively, no differently than a single-large seller in that they all equalize marginal revenues to marginal costs in each period. However, there are interesting intertemporal implications. Recall that storage can be seen as an investment allowing the agent to sell more in the future. Because spot sales are strategic substitutes, it is not surprising that competition between the strategic agents leads to more conservative stock depletion than in the presence of only one firm (i.e., when $i$ is assumed to behave strategically and $j$ is taken as part of the fringe). Thus, the strategic interaction leads both firms to behave more conservatively today (i.e., leaving more stock for tomorrow) by both selling less and abating more. Intuitively, firms behave this way in an attempt to capture larger market share in the future.

In the case of two buyers, case (ii), it is clear that the equilibrium outcome is more competitive since a firm has less of an incentive to delay purchases and depress prices because of free-riding by its rival.

Let us now turn to case (iii) by making $s_{1}^{j}=0$, while maintaining $s_{1}^{i}>0$ and $s_{1}^{f}=0$. Before discussing the case it is instructive to explain what happens in a static context where the strategic seller, $i$, and the strategic buyer, $j$, share the market with the competitive fringe for a single period. To countervail $j$ 's buying power $i$ will sell less (abate less) relative to the case in which $j$ behaves competitively (i.e., is part of the fringe). Likewise, firm $j$ will countervail $i$ 's selling power by buying less (abating more) than if the stock were in competitive hands. The equilibrium price will tend to move closer to competitive levels and eventually may coincide with its perfectly competitive level if buyer and selling powers exactly cancel out. The same strategic forces are present in a dynamic context but with quite different implications for equilibrium prices. The 
presence of an strategic buyer makes firm $i$ to lower the rate at which it sells its stock over time. In terms of our general model, this reaction will unambiguously translate into a less competitive price path (i.e., wider gap between $p_{t}$ and $\delta p_{t+1}$ ) extending even further the depletion phase. This can be readily seen with our two period model. Rearrange equation (48) in the Appendix to obtain

$$
c_{f}^{\prime}\left(q_{1}^{f}\right)-\delta c_{f}^{\prime}\left(q_{2}^{f}\right)=x_{1}^{i} c_{f}^{\prime \prime}\left(q_{1}^{f}\right)-\delta x_{2}^{i} c_{f}^{\prime \prime}\left(q_{2}^{f}\right)-\delta x_{2}^{i} c_{f}^{\prime \prime}\left(q_{2}^{f}\right) \frac{\partial x_{2}^{j}}{\partial s_{2}^{i}}
$$

When $j$ is negligible (i.e., $\partial x_{2}^{j} / \partial s_{2}^{i}=0$ ), we arrive precisely at the equilibrium condition for the single strategic seller where, as we know from the basic model, $c_{f}^{\prime}\left(q_{1}^{f}\right)=p_{1}>$ $\delta p_{2}=\delta c_{f}^{\prime}\left(q_{2}^{f}\right)$. As $j$ grows larger, the gap $c_{f}^{\prime}\left(q_{1}^{f}\right)-\delta c_{f}^{\prime}\left(q_{2}^{f}\right)$ increases in equilibrium since we are adding a positive term (recall that $\left.\partial x_{2}^{j} / \partial s_{2}^{i}<0\right)$.

We conclude this section with a brief discussion on the possibility for the strategic firms to sustain collusion. If we also allow for long-run market power we may no longer treat the stock depletion game as a strictly finite-horizon game. Related to Gul (1987), one could argue that the (subgame-perfect) threat of falling into the (long-run) noncooperative equilibrium may even allow strategic buyers to sustain full monopsony profits during the stock depletion phase.

\subsection{Alternative market structures}

It is natural to focus on the spot market transactions when the objective to understand the primitive determinants of permit valuations over time. However, in view of the different type of market transactions that we observe in the U.S. sulfur market - see, for example, Ellerman et al. (2000) - it is natural to ask whether and how our equilibrium description would change if we extended the scope of the market to cover forward transactions. The demand for forward transactions typically arises due to the need to share risk among market participants, but it is well known that oligopolistic firms can also choose to enter the forward market due to strategic reasons (Allaz and Vila, 1993). Forward contracting of production provides a commitment to a future market share, but leads to a prisoners' dilemma type of situation where firms end up behaving more competitively than without forward markets.

The procompetitive effect of Allaz and Vila (1993) cannot be directly applied to a dynamic market such as the pollution permit market considered here. Liski and Montero (2006b) show that the existence of forward markets increases the scope for collusive outcomes in an oligopolistic setting (i.e., two or more large firms), if the traded good is 
reproducible and interaction is repeated over time. For an exhaustible-resource market a different result may follow: oligopolistic (non-collusive) equilibrium becomes competitive very quickly when forward market interactions are rapid, although asymmetries in stockholdings can help firms to avoid the procompetitive effect coming from contracting (Liski and Montero , 2008). These results are of direct use in the dynamic permit market, but the conclusion depends on further characteristics of the permit market. The long-run market interaction, after the exhaustion of the stock, can in principle continue forever, and, in this case, "deep" markets in the form of forward trading may help to sustain collusion as suggested by the theory.

For policy design, the forward market has the implication that if market manipulation is a concern, it makes sense to require sufficient forward sales of permit stocks. In particular, this can eliminate the potential collusion working through forward markets, and, even when collusion is not a concern, oligopolistic interaction becomes more competitive, the greater is the degree of contract coverage of sales.

\section{Applications}

We illustrate the use of our theory with two applications: the sulfur market of the U.S. Acid Rain Program of the 1990 Clean Air Act Amendments (CAAA) and the carbon market that may eventually develop with and beyond the Kyoto Protocol.

\section{$5.1 \quad$ Sulfur trading}

The market for sulfur dioxide $\left(\mathrm{SO}_{2}\right)$ emissions has been operating since the early 90s; right after the 1990 CAAA allocated allowances/permits to electric utility units for the next 30 years in designated electronic accounts. ${ }^{26}$ We can then make use of agents' actual behaviors, as opposed to hypothetical ones, to check whether the conditions for market manipulation hold. Note that our exercise is by no means a test for market power; for that we would have or estimate marginal abatement cost curves.

The data we use for our exercise, which is publicly available, comprises electric utility units' annual $\mathrm{SO}_{2}$ emissions and allowance allocations from 1995 - the first year of compliance with $\mathrm{SO}_{2}$ limits - through 2003. We purposefully exclude 2004 and later numbers because of the four-fold increase in $\mathrm{SO}_{2}$ allowance prices during 2004-05 in response to the proposed implementation of the Clean Air Interstate Rule, which would effectively

\footnotetext{
${ }^{26}$ For details in market design and performance see Ellerman et al. (2000) and Joskow et al. (1998).
} 
lower the $\mathrm{SO}_{2}$ limits established in the original regulatory design by two-thirds in two steps beginning in 2010. Although this recent price increase provides further evidence that in anticipation of tighter limits firms do respond by building up extra stocks (or by depleting existing stocks less intensively), we concentrate on firms' behavior under the original regulatory design where we have nine years of data and can therefore, make reasonable projections as needed. The long-term emissions goal under the original design is slightly above 9 million tons of $\mathrm{SO}_{2}$.

Following our theory, the exercise consists in identifying potential strategic players and checking whether these players are on the supply or demand side of the market and to what extent. The potential strategic players in our analysis, acting either individually or as a cohesive group, are assumed to be the four largest permit-stock holding companies -American Electric Power, Southern Company, FirstEnergy ${ }^{27}$ and Allegheny Powerthat together account for $42.5 \%$ of the permits allocated during Phase I of the Acid Rain Program, i.e., 1995-1999, which corresponds to the "generous-allocation" phase. ${ }^{28}$ While $s_{0}^{m}$ is readily obtained from agents' cumulative permit allocations, calculating $s_{0}^{m *}$ would seem to require a more elaborate procedure based, perhaps, on some abatement cost estimates. This is not necessarily so because we have actual emissions data.

Table 2 presents a summary of compliance paths for the two largest strategic players, the Group of Four, as well as for all firms. The noticeable discontinuities in 2000 - the first year of Phase II - are due to both a significant decrease in permit allocations and the entry of a large number of previously unregulated sources. ${ }^{29}$ Precisely because of this discontinuity in the regulatory design firms had incentives to build a large stock of permits during Phase I, which reached an aggregate peak of 11.65 million allowance by the end of 1999. Although strategic players, either individually or as a group, present a

\footnotetext{
${ }^{27}$ Note that FirstEnergy was the result of mergers in 1997 and 2001 but for the purpose of this analysis we make the conservative assumption that all mergers were consummated by 1995 .

${ }^{28}$ Their individual shares of Phase I permits are 13.2, 13.5, 9.3 and $6.5 \%$, respectively. The next permit-stock holder is Union Electric Co. with $4.2 \%$ of the permits. Neither was Tennessee Valley Authority (TVA), which received $9.2 \%$ of Phase I permits, considered as part of the potential strategic players for the simple reason that it is a federal corporation that reports to the U.S. Congress. Even if we add these two companies to the group, forming a coalition with $56 \%$ of the market, our conclusions remain unaltered because at the time of the exhaustion of the overall stock TVA shows a deficit of permits while Union Electric a mild surplus.

${ }^{29}$ Some of these unregulated sources voluntarily opted in earlier into Phase I and received permits under the so-called Substitution Provision. Since with very few exceptions opt-in sources have helped utilities to increase their permit stocks (Montero, 1999), for the purpose of our analysis we treat these sources (with their emissions and allocations) as Phase I sources.
} 
significant surplus of permits by 1999 that may be indicative of possible market power problems, ${ }^{30}$ it is also true that these players are rapidly depleting their stocks from the simple fact that their annual emissions are above their annual permit allocations. By 2003, the last year for which we have actual emissions, the stock of the Group of Four is already reduced to 1.11 million allowances while the aggregate stock is still significant at 6.47 million allowances.

\section{*** INSERT TABLE 2 HERE OR BELOW ***}

Taking a linear extrapolation of aggregate emissions from its 2003 level of 10.60 million tons to the long-run emissions limit of 9.12 million tons, we project the aggregate stock of permits to be depleted by 2012, which is very much in line with the more elaborated projections of Ellerman and Montero (2007). Assuming that the share of emissions for the projected years is the same as during 2000-2003, ${ }^{31}$ the numbers in the last row of Table 2 show that the compliance paths followed by the potential strategic players, taken either individually or collectively, do not support, according to our theory, a concern for significant market manipulation. ${ }^{32}$ As established by Propositions 1 and 2 and the discussion that followed, market power is much more of a problem when (potential) strategic players are on the supply side of the market, which does not happen in the sulfur market: all four large firms are net buyers for the 1995-2012 period.

There is a second piece of evidence, based on trading activity, that reinforces our finding that market power is less of a problem in the sulfur market. According to our theory, a large agent exercising buyer-power will never sell permits in the market because this would only move forward the arrival of the long-run equilibrium. However, the EPA allowance tracking system shows significant sales by our four large net-buyers. For example, by the end of year 2000, American Electric Power had sold about 1.1 million of current-vintage allowances and Southern Company about 1.5 million. ${ }^{33}$ These are

\footnotetext{
${ }^{30}$ In reality their actual stocks may be larger or smaller than these figures depending on firms' market trading activity. Our theoretical predictions, however, are independent of trading activity as long as it is observed, which in this particular case can be done with the aid of the U.S. EPA allowance tracking system. We will come back to the issue of imperfect observability in the concluding section.

${ }^{31}$ This is a reasonable assumption in the sense that the extra reduction needed to reach the long-run limit is moderate and not much larger than the reduction that has already taken place in Phase II. In addition, since we know that all firms move along their marginal cost curves at the (common) discount rate regardless of the exercise of market power, their emission shares should not vary much if we believe their marginal cost curves have similar curvatures in the relevant range.

${ }^{32}$ The same argument applies if the overall stock is expected to be depleted much earlier, say, in 2009.

${ }^{33}$ Personal communication with Denny Ellerman on March 2009. It is worth mentioning that obtaining
} 
significant amounts if we compare them to firms' annual allocations.

Our focus has been on transitory market power, i.e., market power during the evolution of the permit stock. Looking at long-run market power, as discussed in Section 4.2, is not feasible without having data on actual long-run behavior. We believe, however, long-run market power to be less of a problem because large players' long-run allocations are greatly reduced in relative terms. The largest player (Southern Company) receives less than $8 \%$ of the total allocation and the Group of Four only 23\%. Any larger coalition of players would be hard to imagine. Moreover, it is quite possible that the long-run market equilibrium would have been dictated by the price of scrubbing technologies capable of removing up to $95 \%$ of $\mathrm{SO}_{2}$ emissions.

\subsection{Carbon trading}

The carbon application differs from the previous application in significant ways. First and most importantly, we do not know yet the type of regulatory institutions -including policy instruments and participants - that will succeed the Kyoto Protocol in the multinational efforts to stabilize carbon emissions, and hence, carbon concentrations in the atmosphere. At this point all we know is that regardless of the regulatory mechanism adopted, there will be a long transition period of a few decades between now and the time of stabilization. And if this transition period is governed by a Kyoto-type market mechanism, then, the global carbon market that will eventually develop will share many of the characteristics of our model. First, firms will have strong incentives to store permits from earlier allocations in an effort to smooth the increase in abatement costs that is required to stabilize emissions in the long-run; and second, there will be large players, i.e., countries or group of countries with ability to manipulate market prices if it is in their best interest to do so. ${ }^{34}$

Even when a country member ends up allocating its permits quota to its domestic firms, which can then be freely traded in the global market, the country can simultaneously resort to alternative domestic policies to "coordinate" the actions of its domestics firms very much like a large agent in our model. For example, a country that wants to exercise downward pressure on global prices can set a subsidy on cleaner but more expen-

estimates of trading activity at the firm level from the EPA allowance tracking system requires an enormous amount of computational effort; not surprisingly, such data has not been produced by EPA.

${ }^{34}$ We are certainly not the first to argue that large countries such as Russia and the U.S. can affect prices. See, for example, Bernard et al. (2003), Manne and Richels (2001), and Hagem and Westskog (1998). 
sive technologies (e.g., some of the renewable energies), and thus, reducing the country's aggregate demand for permits. On the other hand, a country that wants to exercise upward pressure on prices can levy a tariff on permit exports, and thus, depressing the country's aggregate supply of permits. It would be hard to argue against such a measure if the resulting revenues are aimed at financing $R \& D$ on cleaner technologies. ${ }^{35}$

There is another reason to believe that countries/regions - not individual facilitiesare the relevant players for understanding the exercise of market power in a global market for carbon permits. As argued by Jaffe and Stavins (2009), it is very unlikely to see, at least in the medium-term, a truly global carbon market with a unique market price but rather multiple permit markets in different countries/regions. These markets will be (imperfectly) linked to each other so that some exchange of permits will be allowed across markets. Countries, not individual facilities, will decide through different domestic policies how much "linkage" to have with the rest of the world. Hence, the interesting question is under what circumstances a large country would find in its best interest to implement domestic policies or market designs (i.e., introduction of safety valves, subsidies, standards, etc.) that would work as if the country were exercising market power in a truly global market. Or alternatively put, if we observe the implementation of domestic policies that prevent a perfect linkage among the different permit markets to what extent we can claim that these policies are driven by a genuine interest in altering international prices or rather they are the result of internal domestic forces (politics) unrelated to market power.

Our theory can help us to start framing these and related questions. We illustrate now the use of the theory with a simple exercise that does not require extending the model to incorporate many of the elements that would prove relevant in a more comprehensive analysis (e.g., timing and scope of developing countries' participation, treatment of carbon sequestration, etc.). For the same reason our exercise is primarily illustrative. In this simple exercise we ask to what extent the proportions used in the Kyoto Protocol to allocate permits among Annex I (i.e., more developed) countries make the exercise of market power more or less likely in a global carbon market that goes well beyond Kyoto. Using the country classification of the MIT's CGE climate policy model (Babiker et al., 2008) and considering all greenhouse gases (GHG) at their carbon dioxide equivalent (CO2-e), the first three columns of Table 3 show baseline emissions (i.e., emissions in the absence of regulation) for year 2010 and Kyoto allocations for the different Annex

\footnotetext{
${ }^{35}$ This opens up a new question not addressed in our model which is how a large agent would decide on $R \& D$ investments along with abatement and permit transactions.
} 
I regions/countries. Baseline emissions are obtained from MIT's model (Morris et al., 2008) and Kyoto allocations are computed using the latest data from the web site of the United Nations Framework Convention on Climate Change (www.unfccc.int).

\section{*** INSERT TABLE 3 HERE OR BELOW ***}

Based on Hahn's (1984) static framework, it is clear, for example, that regardless of its abatement cost function, FSU would restrict its supply of permits in 2010 in an effort to increase prices above competitive levels. According to our theory, however, FSU would find it advantageous to do so only if its allocation profile during the transition period is above its perfectly competitive emissions path. Babiker et al. (2008) report the perfectly competitive emission paths that would stabilize world GHG emissions by $2050 .{ }^{36}$ The following columns of Table 2 present cumulative baseline GHG emissions and cumulative emissions along the competitive path for the period 2010-2050 and for the different countries/regions. ${ }^{37}$ Assuming that participation in this global carbon market is restricted to Annex I countries - low-cost abatement opportunities from the developing world are brought to the carbon market through alternative but cost-effective institutions - , the numbers in Table 3 suggest that FSU would certainly benefit from manipulating today's prices if it expects its future share of permits to remain at its Kyoto level (24\%). This risk of market manipulation would greatly diminish if the FSU allocation would come closer to $18 \%$. Note that the Kyoto shares of the other parties are surprisingly close to their efficient shares.

\section{Concluding Remarks}

We developed a model of a market for storable pollution permits in which a (or a few) large polluting agent and a fringe of small agents gradually consume a stock of permits until they reach a long-run emissions limit. We characterized the properties of the subgame-perfect equilibrium for different permit allocations and found the conditions under which market power is greatly mitigated. The latter occurs when the large agent's intertemporal permits endowment is below its efficient allocation (i.e., the allocation profile that would cover its total emissions along the perfectly competitive path). In this

\footnotetext{
${ }^{36}$ Babiker et al's (2008) recursive path show equilibrium prices starting at 17 US\$ per ton of CO2-e in 2010 and rising $4 \%$ per year.

${ }^{37}$ We use world emissions from Babiker et al.'s (2008) recursive path. Region and country emissions are computed using data from Morris et al. (2008).
} 
case the large agent has trouble in credibly committing to restrict its purchases below the perfectly competitive level. When the endowment is above the efficient allocation, the large agent exercises market power very much like a large supplier of an exhaustible resource. At least three policy implications come out from these results. The first is that allocations to early years that exceed the large agent's current emissions do not necessarily lead to market power problems if allocations to later years are below future needs (this was the case in the sulfur application). The second implication is that any redistribution of permits from the large agent to small agents will unambiguously make the exercise of market power less likely (some of this was discussed in the carbon application). Closely related to the latter, a third implication is that our results make a stronger case for auctioning off permits instead of allocating them for free (as considered throughout the paper). Assuming that there is an after-auction market where firms can exchange permits, any attempt by the large agent to depress auction prices would be arbitrated by the small fringe players - bidding demand schedules above their true marginal costs - in anticipation to the large agent's incentives to buy additional permits in the after market. ${ }^{38}$

Our model assumes that agents' stock-holdings are observable at the beginning of each period. While the EPA allowance tracking system may significantly facilitate keeping track of agents' stock-holdings in the US sulfur market, ${ }^{39}$ it is still interesting to ask what would happen to our equilibrium solution if we let stock-holdings be somewhat private information (or alternatively, assume that large stockholders can use third parties, e.g., brokers, to hide their identities). Lewis and Schmalensee (1982) have already identified this incomplete information problem for a conventional nonrenewable resource market where agents' reserves are only imperfectly observed. They argue that Salant's (1976) solution no longer holds: the large agent could increase profits (above Salant's) by covertly producing either more or less than its Salant equilibrium output. We see the exact same problems affecting our equilibrium solution. Unfortunately, Lewis and Schmalensee (1976) do not offer much insight as to what the new equilibrium conditions might look like. We think this is an interesting topic for future research.

Uncertainty is another ingredient absent in our model. This may be particularly relevant for the carbon application that shows time-horizons of several decades. There are multiple sources of uncertainty related to different aspects of the problem such as

\footnotetext{
${ }^{38}$ Note that uniform price auctions can suffer from under pricing even for a large number of small bidders (Wilson, 1979).

${ }^{39}$ For a description of the EPA tracking system go to http://www.epa.gov/airmarkets/tracking/.
} 
technology innovation, economic growth, future permit allocations, timing and extent of participation of non-Kyoto countries, etc. How these uncertainties, acting either individually or collectively, could affect the essence of our equilibrium solution is not immediately obvious to us because of the irreversibility associated to the build-up and depletion of the permits stock. Tackling these issues may require to put together the strategic elements found in this paper with those of the literature of investment under uncertainty (e.g., Dixit and Pindyck, 1994).

One can view our sulfur application as one of the few attempts at empirically studying market power in pollution permit trading, ${ }^{40}$ but it is important to emphasize that we do not provide a formal test of market power (a test comparing prices and marginal abatement costs) in part because we do not have reliable estimates of marginal cost curves. Our exercise simply showed that the initial allocations of permits to the large firms made these firms net buyers in the market, ruling out any exercise of market power according to our theory. We nevertheless think it is an interesting area for future research estimating marginal cost curves from publicly available data such as prices and emissions and then comparing those cost figures to actual prices. Notice that finding evidence of market power (i.e., departure from marginal cost pricing) under such a test would open up an entirely new set of theoretical questions as to what could explain the presence of market power beyond that attributed to the initial allocation of permits.

Finally, the theory applied in this paper could also be applied to other exhaustibleresource markets, including the world market for oil. In the oil market, one could perhaps estimate countries efficient own demand and reservoir developments to identify their future positions in this market, and in this way find the countries or regions with highest potential for being in the dominant position today or in the future. The theory suggests that expected future changes in demand infrastructure or reservoir recoveries should influence market performance today.

\section{$7 \quad$ Appendix}

\subsection{Proof of Proposition 1}

We introduce the game first in discrete time to make the extensive form clear. We look for an equilibrium in strategies that condition actions on the state of the market, i.e., equilibrium is Markovian. At the beginning of each period $t=0,1,2, \ldots$ all agents

\footnotetext{
${ }^{40}$ Kolstad and Wolak (2003) is another attempt.
} 
observe the stock holdings of both the large polluter, $s_{t}^{m}$, and the fringe, $s_{t}^{f}$. Having observed stocks $s_{t}^{m}$ and $s_{t}^{f}$ and the large agent's sales $x_{t}^{m}$, fringe members form rational expectations about future supplies by the large agent and make their abatement decision $q_{t}^{f}$ as to clear the market, i.e., $x_{t}^{f}=-x_{t}^{m}$, at a price $p_{t} \geq 0$. It is clear that the fringe abatement strategy depends on the observable triple $\left(x_{t}^{m}, s_{t}^{m}, s_{t}^{f}\right)$, so we will write $q_{t}^{f}=q^{f}\left(x_{t}^{m}, s_{t}^{m}, s_{t}^{f}\right)$. Note that we assume that the fringe does not observe $q_{t}^{m}$ before abating at $t$, so the decisions on abatement are simultaneous (but this is not essential for the results).

At each $t$ and given stocks $\left(s_{t}^{m}, s_{t}^{f}\right)$, the large agent chooses $x_{t}^{m}$ and decides on $q_{t}^{m}$ knowing that the fringe can correctly replicate the large agent's problem in the subgame starting at next period. Let $V^{m}\left(s_{t}^{m}, s_{t}^{f}\right)$ denote the large agent's payoff given $\left(s_{t}^{m}, s_{t}^{f}\right)$. Let $\delta=e^{-r \Delta}$ be the discount factor associated with the discount rate $r>0$ and period length $\Delta>0$. Then, the equilibrium strategy for the large agent $\left\{x^{m}\left(s_{t}^{m}, s_{t}^{f}\right), q^{m}\left(s_{t}^{m}, s_{t}^{f}\right)\right\}$ solves

$$
V^{m}\left(s_{t}^{m}, s_{t}^{f}\right)=\max _{\left\{x_{t}^{m}, q_{t}^{m}\right\}}\left\{\left[p_{t} x_{t}^{m}-c_{m}\left(q_{t}^{m}\right)\right] \Delta+e^{-r \Delta} V^{m}\left(s_{t+\Delta}^{m}, s_{t+\Delta}^{f}\right)\right\}
$$

where

$$
\begin{aligned}
s_{t+\Delta}^{m} & =s_{t}^{m}+\left[a^{m}-u^{m}+q_{t}^{m}-x_{t}^{m}\right] \Delta \\
s_{t+\Delta}^{f} & =s_{t}^{f}+\left[a^{f}-u^{f}+q_{t}^{f}-x_{t}^{f}\right] \Delta \\
x_{t}^{f} & =-x_{t}^{m} \\
q_{t}^{f} & =q^{f}\left(x_{t}^{m}, s_{t}^{m}, s_{t}^{f}\right), \\
p_{t} & =c_{f}^{\prime}\left(q_{t}^{f}\right),
\end{aligned}
$$

and $q^{f}\left(x_{t}^{m}, s_{t}^{m}, s_{t}^{f}\right)$ is the fringe equilibrium strategy.

Interior first-order conditions for $q_{t}^{m}$ and $x_{t}^{m}$ are

$$
\begin{aligned}
& q_{t}^{m}:\left[-c_{m}^{\prime}\left(q_{t}^{m}\right)+e^{-r \Delta} V_{s_{t}^{m}}^{m}\right] \Delta=0 \\
& x_{t}^{m}:\left[p_{t}+\frac{\partial p_{t}}{\partial q_{t}^{f}} \frac{\partial q_{t}^{f}}{\partial x_{t}^{m}} x_{t}^{m}-e^{-r \Delta} V_{s_{t}^{m}}^{m}+e^{-r \Delta} V_{s_{t}^{f}}^{m} \times\left(1+\frac{\partial q_{t}^{f}}{\partial x_{t}^{m}}\right)\right] \Delta=0
\end{aligned}
$$

The equilibrium described in the text can be constructed from these conditions as follows. If $s_{t}^{m}=s_{t}>0$ and $s_{t}^{f}=0$, the large agent is a monopoly in the permit stock market, and then the equilibrium conditions reduce to

$$
\begin{aligned}
&-c_{m}^{\prime}\left(q_{t}^{m}\right)+e^{-r \Delta} V_{s_{t}^{m}}^{m}=0 \\
& c_{f}^{\prime}\left(u^{f}-a^{f}-x_{t}^{m}\right)-c_{f}^{\prime \prime}\left(u^{f}-a^{f}-x_{t}^{m}\right) x_{t}^{m}-e^{-r \Delta} V_{s_{t}^{m}}^{m}=0 .
\end{aligned}
$$


By (23), $V_{s^{m}}^{m}$ equals the marginal cost of using a permit for own abatement. Cost minimization over time implies then that $V_{s^{m}}^{m}$ grows at the rate of interest and, thus, when $\Delta$ is small,

$$
d c_{m}^{\prime}\left(q_{t}^{m}\right) / d t=r c_{m}^{\prime}\left(q_{t}^{m}\right),
$$

until $s^{m}=0$, where $V_{s^{m}}^{m}=c_{m}^{\prime}\left(u^{m}-a^{m}\right)$. Using (24), we obtain

$$
M R_{t}=c_{m}^{\prime}\left(q_{t}^{m}\right)
$$

where $M R_{t}=c_{f}^{\prime}\left(u^{f}-a^{f}-x_{t}^{m}\right)-c_{f}^{\prime \prime}\left(u^{f}-a^{f}-x_{t}^{m}\right) x_{t}^{m}$ is the marginal revenue, given that the fringe is not holding a stock $\left(s_{t}^{f}=0\right)$. Thus, both marginal revenue and marginal cost grow at the rate of interest over time until the large agent exhausts its stock,

$$
d M R_{t} / d t=r M R_{t}
$$

In continuous time, the equilibrium conditions can be expressed as in the text. Note that

$$
\begin{aligned}
M R_{t} & =p_{t}\left[1+\frac{1}{\varepsilon_{t}}\right] \\
\varepsilon_{t} & =\left[\frac{d c_{f}^{\prime}\left(q^{f}\right)}{d q^{f}} \frac{x^{m}}{p}\right]^{-1}=-\frac{d x^{m}}{d p} \frac{p}{x^{m}},
\end{aligned}
$$

where $\varepsilon_{t}$ is the demand elasticity (defined to be positive). Since $\varepsilon_{t}$ increases over time, it follows that

$$
\frac{d M R_{t} / d t}{M R_{t}}=r>\frac{d p_{t} / d t}{p_{t}}
$$

From this we can conclude that the competitive agents do not save permits for future uses along the monopolist's first best solution.

We can now proceed to the main case, where the fringe has some stock $s_{0}^{f}>0$, but has still less than the efficient share $s_{0}^{f}<s_{0}^{f *}$, i.e., $s_{0}^{m *}>s_{0}^{m}$. We proceed immediately to the continuous-time limit and assume that the large agent can commit to path $\left(x_{t}^{m}, q_{t}^{m}\right)_{t \geq 0}$ at $t=0$, and then argue that the path found this way is the subgame-perfect path. After announcing $\left(x_{t}^{m}, q_{t}^{m}\right)_{t \geq 0}$, the large agent understands that the arbitrage will imply $d p_{t} / d t=r p_{t}$ as long as $s_{t}^{f}>0$. Integrating gives

$$
p_{t}=p_{0} e^{r t} \text { for } t \leq T^{f} \text {. }
$$

The large agent's objective can then be written as

$$
\begin{aligned}
& \max \left\{p_{0} \int_{0}^{T^{f}} x_{t}^{m} d t-\int_{0}^{T^{m}} c_{m}\left(q_{t}^{m}\right) e^{-r t} d t\right\}, \text { or } \\
& \max \left\{p_{0} X^{m}-\int_{0}^{T^{m}} c_{m}\left(q_{t}^{m}\right) e^{-r t} d t\right\},
\end{aligned}
$$


where $X^{m}$ is the total amount sold to the market by the large agent during the interval $\left[0, T^{f}\right]$. We can thus express the optimal sales condition as

$$
\frac{\partial p_{0}}{\partial X^{m}} X^{m}+p_{0}=e^{-r T^{f}} M R_{T^{f}}
$$

where the right-hand-side is the discounted marginal revenue from the monopoly phase. Since $M R_{t}$ grows at rate $r$ for $T^{f} \leq t \leq T^{m}$, condition (28) says that the large agent receives the same discounted marginal revenue from all $t \leq T^{m}$. In particular, condition (28) holds if the agent implements the total sale $X^{m}$ by choosing $\left(x_{t}^{m}\right)_{T^{f}>t \geq 0}$ to satisfy (27). The equilibrium conditions are then (25)-(27) plus the fringe arbitrage condition. Note that if $s_{0}^{m *}=s_{0}^{m}$, the socially optimal path $\left(q_{t}^{m *}, q_{t}^{f *}\right)_{t \geq 0}$ with $X^{m}=0$ satisfies the conditions for the commitment solution. If $s_{0}^{m *}>s_{0}^{m}$, the solution requires $0<T^{f}<T^{m}$, and these numbers are found by using the stock-exhaustion conditions together with firstorder conditions.

The path identified this way (and discussed in more detail in the text) is the subgameperfect path if the agent implements the total sale $X^{m}$ by choosing $\left(x_{t}^{m}\right)_{T^{f}>t \geq 0}$ to satisfy (27). In this case, the stocks $\left(s_{t}^{m}, s_{t}^{f}\right)_{t \geq 0}$ develop along the equilibrium path such that the analog of condition (28) evaluated at any future point $t \leq T^{f}$ continues to hold: the large agent has no reason revise the plan. In contrast, if the total sale $X^{m}$ was made at $t=0$, the stocks would go off the subgame-equilibrium path. The path defined in this way is consistent and the supporting strategies can be written as state-dependent rules without influencing the path. In our working paper, Liski and Montero (2005), we do this for a discrete-time version of the model.

\subsection{Proof of Proposition 2}

When $s_{0}^{m}<s_{0}^{m *}$, the large firm is a buyer of permits during some part of the equilibrium path. In continuous time, we can express the buyer's equilibrium payoff as

$$
V^{m}\left(s_{t}^{m}, s_{t}^{f}\right)=\int_{t}^{T}\left[p_{t} x_{t}^{m}-c_{m}\left(q_{t}^{m}\right)\right] e^{-r(\tau-t)} d \tau+e^{-r(T-t)} V^{m}(0,0)
$$

where $T$ is the exhaustion time, and $V^{m}(0,0)$ is equal to the long-run compliance cost, i.e., $-c_{m}\left(u^{m *}-a^{m *}\right) / r$.

When time is discrete but period length $\Delta$ is short, we can express the buyer's payoff as

$$
V^{m}\left(s_{t}^{m}, s_{t}^{f}\right)=\left[p_{t} x_{t}^{m}-c_{m}\left(q_{t}^{m}\right)\right] \Delta+e^{-r \Delta} V^{m}\left(s_{t+\Delta}^{m}, s_{t+\Delta}^{f}\right) .
$$


We derive the equilibrium conditions for the case $s_{t}^{m}=0$ and $s_{t}^{f}>0$, i.e., the large agent has no stock of its own but is buying from the fringe to comply. As explained in the text, this must be the case in the final part of the equilibrium path. Now, the large agent's choice is effectively only $x_{t}^{m}$ since $q_{t}^{m}=u^{m}-a^{m}+x_{t}^{m}$ when $s_{t}^{m}=0$. The interior first order condition is then

$$
\left[p_{t}+\frac{\partial p_{t}}{\partial q_{t}^{f}} \frac{\partial q_{t}^{f}}{\partial x_{t}^{m}} x_{t}^{m}-c_{m}^{\prime}\left(q_{t}^{m}\right)+e^{-r \Delta} V_{s_{t}^{f}}^{m} \times\left(1+\frac{\partial q_{t}^{f}}{\partial x_{t}^{m}}\right)\right] \Delta=0 .
$$

As $\Delta \rightarrow 0$, this reduces to

$$
p_{t}-c_{m}^{\prime}\left(q_{t}^{m}\right)+V_{s_{t}^{f}}^{m}=0
$$

When the fringe is holding stocks and $\Delta \rightarrow 0$, the price today depends only on the expected price tomorrow which, in turn, is given by the stocks left for tomorrow. The effect of $x_{t}^{m}$ on stock and thus on price is captured in the term $V_{s^{f}}^{m}$, and, hence, $x_{t}^{m}$ has no independent price effect today, $\partial q_{t}^{f} / \partial x_{t}^{m}=0$.

To find an expression for $V_{s_{t}^{f}}^{m}$, totally differentiate $V^{m}$ to get

$$
\begin{aligned}
d s_{t}^{f} V^{m}= & d V^{m} \\
& \int_{t}^{T}\left[p_{\tau}+\frac{\partial p_{\tau}}{\partial q_{\tau}^{f}} \frac{\partial q_{\tau}^{f}}{\partial x_{\tau}^{m}} x_{\tau}^{m}\right] d x_{\tau}^{m} e^{-r(\tau-t)} d \tau+ \\
& \int_{t}^{T} c_{m}^{\prime}\left(q_{\tau}^{m}\right) d q_{\tau}^{m} e^{-r(\tau-t)} d \tau+ \\
& e^{-r(T-t)}\left[p_{t} x_{t}^{m}-c_{m}\left(q_{t}^{m}\right)-r V^{m}(0,0)\right] d T+ \\
& \int_{t}^{T} x_{\tau}^{m} d p_{\tau} e^{-r(\tau-t)} d \tau .
\end{aligned}
$$

Lines (31) and (32) are zero because we are evaluating these changes along the equilibrium path: marginal perturbation of the equilibrium choice variable must yield a zero improvement in value (recall that $x_{t}^{m}$ is effectively the only choice variable). Line (33) is also zero because the long-run reached at $T$, and $x_{T}^{m}=0$ and $c_{m}\left(q_{T}^{m}\right)=-r V^{m}(0,0)=$ $c_{m}\left(u^{m *}-a^{m *}\right)$. The last term on line (34) is the marginal change in the purchase cost due to price change. Write

$$
\int_{t}^{T} x_{\tau}^{m} p_{\tau} e^{-r(\tau-t)} d \tau=e^{-r(T-t)} \bar{p} \int_{t}^{T} x_{\tau}^{m} d \tau=e^{-r(T-t)} \bar{p} X_{t} .
$$

The first equality follows from the fact that prices grow at the rate of interest (fringe is holding permits to the point $T$ ). The second equality uses $X_{t}$ as a shorthand for total purchases at $t$, along the equilibrium path. Since $\bar{p}$ is fixed (the long-run price), the price 
effect comes only from the postponement of the choke price, and thus the expression for $d s_{t}^{f} V^{m}$ simplifies to

$$
d s_{t}^{f} V_{s_{t}^{f}}^{m}=-r e^{-r(T-t)} \bar{p} X_{t} d T=-r p_{t} X_{t} d \tau
$$

where $d T=d \tau$ because the marginal increase in $T$ equals the period length. Since also $d t=d \tau$ and $d s_{t}^{f}=\left[a^{f}-u^{f}+q_{t}^{f}-x_{t}^{f}\right] d t$, we can write

$$
V_{s_{t}^{f}}^{m}=\frac{r p_{t} X_{t}}{u_{t}^{f}-a_{t}^{f}-q_{t}^{f}+x_{t}^{f}}
$$

Using this expression, rewrite now the first-order condition (29), as

$$
c_{m}^{\prime}\left(q_{t}^{m}\right)-p_{t}=\frac{r p_{t} X_{t}}{u_{t}^{f}-a_{t}^{f}-q_{t}^{f}+x_{t}^{f}}>0
$$

for all $t<T$ where $X_{t}>0$. This is the condition presented in the text.

If we fix $T, X_{t}$ can be solved from

$$
X_{t}=-\int_{t}^{T} x_{\tau}^{f} d \tau=s_{t}^{f}-\left(a^{f}-u^{f}\right)(T-t)-\int_{t}^{T} q_{\tau}^{f} d \tau,
$$

where $q_{\tau}^{f}$ is given by the condition

$$
c_{f}^{\prime}\left(q_{\tau}^{f}\right)=p_{\tau}=\bar{p} e^{-r(T-\tau)}
$$

Also,

$$
-x_{t}^{f}=x_{t}^{m}=a^{m}-u^{m}+q_{t}^{m} .
$$

Using (36)-(39), we can solve $q_{t}^{m}$ as a function of $s_{t}^{f}$ and $T$, i.e., $q_{t}^{m}=q^{m}\left(s_{t}^{f}, T\right)$. Then, we can use this in the fringe budget constraint:

$$
d s_{t}^{f} / d t=a^{f}-u^{f}+q_{t}^{f}-u^{m}+a^{m}+q^{m}\left(s_{t}^{f}, T\right) .
$$

Equation (40) can now be (numerically) solved with the boundary condition $s_{T}^{f}=0$. This will determine the path $\left(s_{\tau}^{f}\right)_{T \geq \tau \geq t}$ and the terminal time $T$.

\subsection{Multiple large firms}

Consider case (i) as described in the text. We proceed by backward induction. At $t=2$ and for any given stock vector $\left(s_{2}^{i}, s_{2}^{j}\right)$, firm $i=i, j$ solves

$$
\max _{x_{2}^{i}} p_{2}\left(x_{2}^{i}, x_{2}^{j}\right) x_{2}^{i}-c_{i}\left(q_{2}^{i}\right)
$$


where $q_{2}^{i}=u^{i}-a^{i}-s_{2}^{i}+x_{2}^{i}, p_{2}\left(x_{2}^{i}, x_{2}^{j}\right)=c_{f}^{\prime}\left(q_{2}^{f}\right)$ and $q_{2}^{f}=u^{f}-a^{f}-x_{2}^{i}-x_{2}^{j}$. Solving the first-order condition (FOC)

$$
c_{f}^{\prime}\left(q_{2}^{f}\right)-x_{2}^{i} c_{f}^{\prime \prime}\left(q_{2}^{f}\right)-c_{i}^{\prime}\left(q_{2}^{i}\right)=0
$$

for both $i$ and $j$, we obtain the subgame-perfect quantity $x_{2}^{i}\left(s_{2}^{i}, s_{2}^{j}\right)$ and profit

$$
\pi_{2}^{i}\left(s_{2}^{i}, s_{2}^{j}\right)=p_{2}\left(x_{2}^{i}\left(s_{2}^{i}, s_{2}^{j}\right), x_{2}^{j}\left(s_{2}^{i}, s_{2}^{j}\right)\right) x_{2}^{i}\left(s_{2}^{i}, s_{2}^{j}\right)-c_{i}\left(q_{2}^{i}=x_{2}^{i}\left(s_{2}^{i}, s_{2}^{j}\right)-s_{2}^{i}+u^{i}\right) .
$$

At $t=1$ firm $i$ must decide on two independent variables, $x_{1}^{i}$ and $q_{1}^{i}$; hence, it solves

$$
\max _{x_{1}^{i}, q_{1}^{i}} p_{1}\left(x_{1}^{i}, x_{1}^{j}\right) x_{1}^{i}-c_{i}\left(q_{1}^{i}\right)+\delta \pi_{2}^{i}\left(s_{2}^{i}, s_{2}^{j}\right)
$$

where $p_{1}\left(x_{1}^{i}, x_{1}^{j}\right)=c_{f}^{\prime}\left(q_{1}^{f}\right), q_{1}^{f}=u^{f}-x_{1}^{i}-x_{1}^{j}, \pi_{2}^{i}\left(s_{2}^{i}, s_{2}^{j}\right)$ is given by (42) and

$$
s_{2}^{i}=s_{1}^{i}-u^{i}+q_{1}^{i}-x_{1}^{i}
$$

The FOC's for $x_{1}^{i}$ and $q_{1}^{i}$ are, respectively

$$
\begin{gathered}
c_{f}^{\prime}\left(q_{1}^{f}\right)-x_{1}^{i} c_{f}^{\prime \prime}\left(q_{1}^{f}\right)+\delta \frac{\partial \pi_{2}^{i}}{\partial s_{2}^{i}} \frac{\partial s_{2}^{i}}{\partial x_{1}^{i}}=0 \\
-c_{i}^{\prime}\left(q_{1}^{i}\right)+\delta \frac{\partial \pi_{2}^{i}}{\partial s_{2}^{i}} \frac{\partial s_{2}^{i}}{\partial q_{1}^{i}}=0
\end{gathered}
$$

Since $\partial s_{2}^{i} / \partial q_{1}^{i}=-\partial s_{2}^{i} / \partial x_{1}^{i}=1$, we obtain that in equilibrium

$$
c_{f}^{\prime}\left(q_{1}^{f}\right)-x_{1}^{i} c_{f}^{\prime \prime}\left(q_{1}^{f}\right)-c_{i}^{\prime}\left(q_{1}^{i}\right)=0
$$

From looking at (41), (46) and (13), one may argue that the two strategic sellers behave, at least qualitatively, no differently than a single-large seller in that they all equalize marginal revenues to marginal costs in each period.

There are important intertemporal differences, however. From the envelope theorem, we know that

$$
\frac{\partial \pi_{2}^{i}\left(s_{2}^{i}, s_{2}^{j}\right)}{\partial s_{2}^{i}}=x_{2}^{i} \frac{\partial p_{2}}{\partial x_{2}^{j}} \frac{\partial x_{2}^{j}\left(s_{2}^{i}, s_{2}^{j}\right)}{\partial s_{2}^{i}}-c_{i}^{\prime}\left(q_{2}^{i}\right) \frac{\partial q_{2}^{i}\left(x_{2}^{i}, s_{2}^{i}\right)}{\partial s_{2}^{i}}
$$

Since $\partial q_{2}^{i} / \partial s_{2}^{i}=-1$ and $\partial p_{2} / \partial x_{2}^{j}=-c_{f}^{\prime \prime}\left(q_{2}^{f}\right)$, replacing (47) into (44) and (45), using (46) and rearranging we obtain

$$
\begin{gathered}
c_{f}^{\prime}\left(q_{1}^{f}\right)-x_{1}^{i} c_{f}^{\prime \prime}\left(q_{1}^{f}\right)+\delta x_{2}^{i} c_{f}^{\prime \prime}\left(q_{2}^{f}\right) \frac{\partial x_{2}^{j}}{\partial s_{2}^{i}}=\delta\left[c_{f}^{\prime}\left(q_{2}^{f}\right)-x_{2}^{i} c_{f}^{\prime \prime}\left(q_{2}^{f}\right)\right] \\
c_{i}^{\prime}\left(q_{1}^{i}\right)+\delta x_{2}^{i} c_{f}^{\prime \prime}\left(q_{2}^{f}\right) \frac{\partial x_{2}^{j}}{\partial s_{2}^{i}}=\delta c_{i}^{\prime}\left(q_{2}^{i}\right)
\end{gathered}
$$


Clearly the equilibrium conditions above differ from those corresponding to the large seller, i.e., eqs. (11) and (12), respectively. Too see why is this, note first that when the large seller plays against the fringe, the first term on the right-hand-side of (47) is zero - fringe firms take prices as given - which leads to (11) and (12). In the presence of a strategic player, firm $i$ must also incorporate the effect that its current decisions have on tomorrow's profits through $j$ 's strategic reaction. The latter is captured by the strategic term $\delta x_{2}^{i} c_{f}^{\prime \prime} \partial x_{2}^{j}\left(s_{2}^{i}, s_{2}^{j}\right) / \partial s_{2}^{i}=-\delta x_{2}^{i}\left[\partial p_{2} / \partial x_{2}^{j}\right]\left[\partial x_{2}^{j}\left(s_{2}^{i}, s_{2}^{j}\right) / \partial s_{2}^{i}\right]$, which is negative since a larger second-period stock necessarily produces a contraction in $j$ 's second-period sales. ${ }^{41}$

More interestingly, this strategic interaction leads $i$ (and $j$ ) to behave more conservatively today (i.e., leaving more stock for tomorrow) by both selling less and abating more. As formally shown in (48), abating an extra unit today carries the additional benefit of increasing the stock available for tomorrow $\left(\partial s_{2}^{i} / \partial q_{1}^{i}>0\right.$; see (43)), which induces $j$ to sell less tomorrow $\left(\partial x_{2}^{j} / \partial s_{2}^{i}<0\right)$, which in turn, puts upward pressure on $p_{2}\left(\partial p_{2} / \partial x_{2}^{j}<0\right)$. The same logic explains why the strategic interaction in (49) makes $i$ to sell a bit less. Because of this strategic interaction marginal costs and marginal revenues will go up at a rate strictly lower than the interest rate in equilibrium. ${ }^{42}$ Overall, however, the two sellers will behave more competitively relative to a cartel compromising the two firms.

\section{References}

[1] Allaz, B., and J.-L. Vila (1993), Cournot competition, forward markets and efficiency, Journal of Economic Theory 59, 1-16.

\footnotetext{
${ }^{41}$ An expression for $\partial x_{2}^{j}\left(s_{2}^{i}, s_{2}^{j}\right) / \partial s_{2}^{i}$ can be obtained from total differentiating expression (46) with respect to $s_{2}^{i}$ for both $i$ and $j$ and then simultaneously solving for $\partial x_{2}^{j}\left(s_{2}^{i}, s_{2}^{j}\right) / \partial s_{2}^{i}$ and $\partial x_{2}^{i}\left(s_{2}^{i}, s_{2}^{j}\right) / \partial s_{2}^{i}$. If, for example, $c_{f}^{\prime \prime \prime}\left(q_{t}^{f}\right)=0$, then

$$
\frac{\partial x_{2}^{j}\left(s_{2}^{i}, s_{2}^{j}\right)}{\partial s_{2}^{i}}=\frac{-c_{i}^{\prime \prime} c_{f}^{\prime \prime}}{3\left[c_{f}^{\prime \prime}\right]^{2}+2 c_{f}^{\prime \prime}\left[c_{i}^{\prime \prime}+c_{j}^{\prime \prime}\right]+c_{i}^{\prime \prime} c_{j}^{\prime \prime}}<0
$$

${ }^{42} \mathrm{It}$ is also worth commenting that the analogy between the large polluting seller and the large supplier of a conventional exhaustible resource (with no extraction costs or constant marginal costs) does no longer hold for the case of multiple strategic sellers. In the absence of extraction costs, marginal revenues continue growing at the rate of interest for the exhaustible-resource suppliers. The analogy can be reestablished if we let the exhaustible-resource suppliers have extraction costs dependent on the overall stock.
} 
[2] Ausubel, L. M., and R. J. Deneckere (1989), Reputation in bargaining and durable goods monopoly, Econometrica 57, 511-531.

[3] Babiker, M., A. Gurgel, S. Paltsev and J. Reilly (2008), A Forward Looking Version of the MIT Emissions Prediction and Policy Analysis (EPPA) Model, Report No. 161 (May), Joint Program on the Science and Policy of Global Change, MIT.

[4] Bernard A., S. Paltsev, J. Reilly, M. Vielle and L. Viguier (2003), Russia's role in the Kyoto Protocol, Report No. 98 (June), Joint Program on the Science and Policy of Global Change, MIT.

[5] Bulow, J. (1982), Durable-good monopolists, Journal of Political Economy 90, 314332.

[6] Coase, R. (1972), Durability and monopoly, Journal of Law and Economics 15, 143-149.

[7] Dixit, A. and R. Pindyck (1994), "Investment under Uncertainty", Princeton University Press, New Jersey.

[8] Ellerman, A.D, P. Joskow, R. Schmalensee, J.-P. Montero, and E.M. Bailey (2000), Markets for Clean Air: The US Acid Rain Program, Cambridge University Press, Cambridge, UK.

[9] Ellerman, A.D., and J.-P. Montero (2007), The efficiency and robustness of allowance banking in the U.S. Acid Rain Program, The Energy Journal 28, 47-71.

[10] Gilbert, R. (1978), Dominant Firm Pricing with Exhaustible Resources, Bell Journal of Economics 9, 385-395.

[11] Gul, F. (1987), Noncooperative collusion in durable goods oligopoly, The RAND Journal of Economics, Vol. 18, No. 2, pp. 248-254

[12] Goulder, L., and Mathai, K. (2000), Optimal CO2 abatement in the presence of induced technological change, Journal of Environmental Economics and Management 39, 1-38.

[13] Hahn, R. (1984), Market power and transferable property rights, Quarterly Journal of Economics 99, 753-765. 
[14] Hagem, C., and H. Westskog (1998), The design of a dynamic tradable quota system under market imperfections, Journal of Environmental Economics and Management, 36, 89-107.

[15] Hendricks K., and R.P. McAfee (2009), A theory of bilateral oligopoly, University of Texas at Austin, forthcoming Economic Inquiry

[16] Hotelling, H. (1931), The economics of exhaustible resources, Journal of Political Economy 39, 137-175.

[17] Jaffe, J., and R. Stavins (2009), Linkage of tradeable permit systems in international climate policy architecture, Harvard University, mimeo.

[18] Joskow, P., R. Schmalensee and E.M. Bailey (1998), The market for sulfur dioxide emissions, American Economic Review 88, 669-685.

[19] Kahn, C. (1986), The durable goods monopolist and consistency with increasing costs, Econometrica 54, 275-94.

[20] Karp, L. and D. Newbery (1993), Intertemporal Consistency Issues in Depletable Resources, In Handbook of Natural Resource and Energy Economics vol. 3, A.V. Kneese and J.L. Sweeney (Eds.), Amsterdam, North Holland.

[21] Kolstad, J. and F. Wolak (2003), Using Environmental Emissions Permit Prices to Raise Electricity Prices: Evidence from the California Electricity Market, University of California Energy Institute, working paper 113.

[22] Lewis, T. and R.Schmalensee (1980), On oligopolistic markets for nonrenewable resources, Quarterly Journal of Economics 95, 475-491.

[23] Lewis, T. and R.Schmalensee (1982), Cartel deception in nonrenewable resource markets, Bell Journal of Economics 13, 263-271.

[24] Liski, M., and Juan-Pablo Montero (2005), Market power in an exhaustible resource market: The case of storable pollution permits, MIT-CEEPR working paper.

[25] Liski, M. and J.-P. Montero (2006a), On pollution permit banking and market power, Journal of Regulatory Economics 28, 283-302.

[26] Liski, M. and J.-P. Montero (2006b), Forward trading and collusion in oligopoly, Journal of Economic Theory, Volume 131, 212-230. 
[27] Liski, M., and J.-P. Montero (2008), Forward trading in exhaustible-resource oligopoly, MIT-CEEPR working paper, WP-2008-006.

[28] Liski, M., and J.-P. Montero (2009), On Coase and Hotelling, MIT-CEEPR working paper, WP-2009-003.

[29] Malueg, D., and A. Yates (2009), Bilateral oligopoly, private information, and pollution permit markets, Environmental and Resource Economics, forthcoming.

[30] Montero, J.-P. (1999), Voluntary compliance with market-based environmental policy: Evidence from the U.S. Acid Rain Program, Journal of Political Economy 107, 998-1033.

[31] Morris, J., S. Paltsev and J. Reilly (2008), Marginal Abatement Costs and Marginal Welfare Costs for Greenhouse Gas Emissions Reductions: Results from the EPPA Model, Report No. 164 (November), Joint Program on the Science and Policy of Global Change, MIT.

[32] Newbery, D.M. (1981), Oil prices, cartels and the problem of dynamic inconsistency, Economic Journal 91, 617-646.

[33] Rubin, J.D. (1996), A model of intertemporal emission trading, banking, and borrowing, Journal of Environmental Economics and Management 31, 269-286.

[34] Salant, S.W. (1976), Exhaustible resources and industrial structure: A NashCournot approach to the world oil market, Journal of Political Economy 84, 10791093.

[35] Tietenberg, T. (2006), Emissions Trading: Principles and Practice, Resources for the Future, Washington, DC.

[36] Williams, J. C. and B. D. Wright (1991), Storage and Commodity Markets. Cambridge, UK: Cambridge University Press.

[37] Wilson, R. (1979), Auctions of shares, Quarterly Journal of Economics 93, 675-89. 
Table 2: Evolution of largest holding companies' compliance paths in the sulfur market

\begin{tabular}{rrrrrrrrr}
\hline \hline & \multicolumn{2}{c}{ American Elec. Power } & \multicolumn{2}{c}{ Southern Company } & \multicolumn{2}{c}{ Group of Four } & \multicolumn{2}{c}{ All firms } \\
Year & Permits & Emissions & Permits & Emissions & Permits & Emissions & Permits & Emissions \\
\hline 1995 & $1,194,410$ & 739,322 & $1,079,502$ & 534,392 & $3,607,506$ & $2,049,809$ & $8,694,296$ & $5,298,617$ \\
1996 & $1,182,429$ & 926,215 & $1,079,085$ & 565,097 & $3,591,282$ & $2,259,687$ & $8,271,366$ & $5,433,351$ \\
1997 & 883,634 & 959,556 & 991,297 & 591,411 & $3,001,934$ & $2,312,083$ & $7,108,052$ & $5,474,440$ \\
1998 & 883,634 & 871,738 & 991,297 & 642,093 & $3,001,728$ & $2,229,636$ & $7,033,671$ & $5,298,498$ \\
1999 & 883,634 & 723,589 & 991,297 & 614,790 & $3,001,809$ & $2,088,510$ & $6,991,170$ & $4,944,666$ \\
2000 & 663,514 & $1,136,095$ & 734,464 & $1,048,296$ & $2,121,591$ & $3,307,858$ & $9,714,830$ & $11,202,052$ \\
2001 & 663,514 & 998,620 & 734,464 & 957,872 & $2,119,625$ & $3,090,712$ & $9,307,565$ & $10,631,343$ \\
2002 & 663,514 & 979,653 & 734,464 & 959,338 & $2,119,625$ & $3,059,693$ & $9,282,297$ & $10,175,057$ \\
2003 & 653,062 & $1,039,413$ & 728,778 & 988,245 & $2,103,487$ & $3,161,696$ & $9,123,376$ & $10,595,945$ \\
2004 & 653,062 & $1,017,878$ & 728,778 & 969,568 & $2,103,487$ & $3,096,652$ & $9,123,376$ & $10,432,326$ \\
$\ldots$ & & & & & & & & \\
2012 & 653,062 & 890,164 & 728,778 & 847,915 & $2,103,487$ & $2,708,114$ & $9,123,376$ & $9,123,376$ \\
$\begin{array}{r}\text { TOTALS } \\
\text { Cumulative }\end{array}$ & & & & & & & & \\
by 1999 & $5,027,741$ & $4,220,420$ & $5,132,478$ & $2,947,783$ & $16,204,259$ & $10,939,725$ & $38,098,555$ & $26,449,572$ \\
$\begin{array}{r}\text { diff. 1999 } \\
\text { Cumulative }\end{array}$ & & 807,321 & & $2,184,695$ & & $5,264,534$ & & $11,648,983$ \\
by 2003 & $7,671,345$ & $8,374,201$ & $8,064,648$ & $6,901,534$ & $24,668,587$ & $23,559,684$ & $75,526,623$ & $69,053,969$ \\
$\begin{array}{r}\text { diff. 2003 } \\
\text { Cumulative }\end{array}$ & & $-702,856$ & & $1,163,114$ & & $1,108,903$ & & $6,472,654$ \\
by 2012 & $13,548,903$ & $16,960,388$ & $14,623,650$ & $15,080,208$ & $43,599,970$ & $49,681,131$ & $157,637,007$ & $157,054,629$ \\
diff. 2012 & & $-3,411,485$ & & $-456,558$ & & $-6,081,161$ & & 582,378 \\
\hline
\end{tabular}

Table 3: Emissions and allocations in a global carbon market beyond Kyoto

\begin{tabular}{lcccccc}
\hline & \multicolumn{3}{c}{ Kyoto period: 2010} & \multicolumn{3}{c}{ Transition period: 2010-2050 } \\
& $\begin{array}{c}\text { Baseline } \\
\text { emissions } \\
\text { Gg CO2-e }\end{array}$ & $\begin{array}{c}\text { Kyoto } \\
\text { allocations } \\
\text { Gg CO2-e }\end{array}$ & $\begin{array}{c}\text { Kyoto } \\
\text { share }\end{array}$ & $\begin{array}{c}\text { Baseline } \\
\text { emissions } \\
\text { Gg CO2-e }\end{array}$ & $\begin{array}{c}\text { Efficient path } \\
\text { Gg CO2-e }\end{array}$ & $\begin{array}{c}\text { Efficient } \\
\text { share }\end{array}$ \\
\hline FSU & 3.61 & 4.37 & $24 \%$ & 219.45 & 131.59 & $18 \%$ \\
USA & 7.68 & 5.71 & $32 \%$ & 457.58 & 285.09 & $40 \%$ \\
EUR & 5.11 & 4.00 & $22 \%$ & 292.55 & 160.38 & $22 \%$ \\
Rest of AnnexI & 4.07 & 3.89 & $22 \%$ & 232.37 & 143.48 & $20 \%$ \\
Total Annex I & 20.47 & 17.96 & $100 \%$ & 1201.95 & 720.55 & $100 \%$ \\
Total World & 40.07 & & & 2527.77 & 1712.05 & \\
\hline
\end{tabular}

Notes: FSU = Former Soviet Union; EUR = European Union (EU-15) plus countries of the European Free Trade Area 